Um algoritmo evolutivo para o problema de dimensionamento de lotes em fundições de mercado

Victor Claudio Bento de Camargo 
SERVIÇO DE PÓS-GRADUAÇÃO DO ICMC-USP

Data de Depósito: 19/02/2009

Assinatura:

\title{
Um algoritmo evolutivo para o problema de dimensionamento de lotes em fundições de mercado ${ }^{1}$
}

\author{
Victor Claudio Bento de Camargo
}

Orientadora: Profa. Dra. Franklina Maria Bragion de Toledo

Dissertação apresentada ao Instituto de Ciências Matemáticas e de Computação - ICMC-USP, como parte dos requisitos para obtenção do título de Mestre em Ciências de Computação e Matemática Computacional.

USP - São Carlos

Fevereiro/2009

${ }^{1}$ Este trabalho foi financiado pela FAPESP 


\section{Resumo}

Segundo uma pesquisa recente realizada junto ao setor de fundições, uma importante preocupação do setor é melhorar seu planejamento de produção. Um plano de produção em uma fundição envolve duas etapas interdependentes: a determinação das ligas a serem fundidas e dos lotes que serão produzidos. Neste trabalho, estudamos o problema de dimensionamento de lotes para fundições de pequeno porte, cujo objetivo é determinar um plano de produção de mínimo custo. Como sugerido na literatura, a heurística proposta trata as etapas do problema de forma hierárquica: inicialmente são definidas as ligas e, posteriormente, os lotes que são produzidos a partir delas. Para a solução do problema, propomos um algoritmo genético que explora um conjunto de possibilidades para a determinação das ligas e utiliza uma heurística baseada em relaxação lagrangiana para determinação dos itens a serem produzidos. Além disso, uma abordagem para o mesmo problema é proposta utilizando o problema da mochila para determinar os itens a serem produzidos. Bons resultados foram obtidos pelos métodos propostos. 



\section{Abstract}

According to a recent research made by the foundry sector, one of the most concern of the industry is to improve its production planning. A foundry production plan involves two independent stages: the determination of alloys to be merged and the lots that will be produced. In this work, we studied the lot-sizing problem for small foundries, whose purpose is to determine a plan of minimum production cost. As suggested in the literature, the heuristic proposed addresses the problem stages in a hierarchical way: first we define the alloys and, subsequently, the lots that are produced from them. We propose a genetic algorithm that explores some possible sets of alloys produced and uses a Lagrangian heuristic to determine the items to be produced. Also, we propose one approach to the same problem that uses the knapsack problem to determine the items to be produced. Good results were obtained by the methods proposed. 



\section{Sumário}

1 Introdução $\quad$ p. 1

2 Revisão Bibliográfica $\quad$ p. 3

2.1 Fundições de grande e de médio porte . . . . . . . . . . . . p. 4

2.2 Fundições de pequeno porte . . . . . . . . . . . . . . p. 5

2.3 Outras aplicações . . . . . . . . . . . . . . . . p. p 7

3 Problema estudado $\quad$ p. 9

4 Abordagem utilizada $\quad$ p. 13

5 Método proposto $\quad$ p. 17

5.1 Codificação do cromossomo . . . . . . . . . . . . . . p. 18

5.2 População inicial . . . . . . . . . . . . . . . . . p. 20

5.3 Cruzamento . . . . . . . . . . . . . . . . . . p. 20

5.4 Mutação . . . . . . . . . . . . . . . . . . . . . p. 22

5.5 Mecanismo de seleção . . . . . . . . . . . . . . . . . . p. 22

5.6 Avaliação do indivíduo . . . . . . . . . . . . . . . . . . p. 23

5.6 .1 Relaxação lagrangiana . . . . . . . . . . . . . . . p. 24

5.6.2 Heurística lagrangiana . . . . . . . . . . . . . p. 25

5.7 Estrutura de árvore . . . . . . . . . . . . . . . . p. 25

5.8 Busca local . . . . . . . . . . . . . . . . . p. 26

5.9 Path relinking . . . . . . . . . . . . . . . . . . p. 27 
6 Testes computacionais para a abordagem de avaliação via heurística $\begin{array}{lr}\text { lagrangiana } & \text { p. } 29\end{array}$

6.1 Cálculo dos custos de atraso e de antecipação . . . . . . . . . . . . p. 29

6.2 Definição dos componentes do algoritmo genético . . . . . . . . . . p. 30

6.2.1 Geração da população inicial . . . . . . . . . . . . . . . . p. 30

6.2 .2 Cruzamento . . . . . . . . . . . . . . . . . p. 31

6.2 .3 Taxa de mutação . . . . . . . . . . . . . . . . . . . . . p. 31

6.2.4 Mecanismo de seleção . . . . . . . . . . . . . . . p. 33

6.2 .5 Busca local . . . . . . . . . . . . . . . . p. 34

6.2.6 Path relinking . . . . . . . . . . . . . . . . p. 34

6.2 .7 Critério de parada . . . . . . . . . . . . . p. 35

6.3 Problemas sem penalidade para subutilização do forno . . . . . . . p. 36

6.4 Problemas com penalidade para subutilização do forno $\ldots \ldots$. . . . p. 38

7 Abordagem pelo problema de corte unidimensional p. 41

7.1 Método de enumeração implícita para o problema da mochila restrita . p.42

7.2 Outros componentes para o algoritmo genético . . . . . . . . . . . p. 44

8 Testes computacionais para a abordagem de avaliação via problema da mochila

8.1 Problemas sem penalidade para subutilização do forno . . . . . . . . p. p. 45

8.2 Problemas com penalidade para subutilização do forno $\quad \ldots$. . . . . . p. 47

8.3 Comparações entre os métodos propostos . . . . . . . . . . . . . . p. 48

9 Conclusões e trabalhos futuros $\quad$ p. 51

Referências Bibliográficas p. 55 


\section{Introdução}

Em 2005, o Brasil ocupava o sétimo lugar como maior produtor mundial de fundidos. Nesta época, o setor de fundição no Brasil era responsável pela geração de 60 mil empregos diretos, $90 \%$ das quais estavam em fundições de pequeno ou médio porte (ABIFA, 2005). Para manter a competitividade ante aos grandes produtores mundiais, é imprescindível a busca continua de novas técnicas que permitam atingir elevados índices de eficiência e baixos custos operacionais. O planejamento da produção é um dos principais fatores que influenciam a produtividade industrial e em uma pesquisa realizada junto aos diretores industriais de fundições é mostrada a preocupação relacionada à importância em melhorar o planejamento de produção (FERNANDES; LEITE, 2002). Nesta pesquisa, foram analisados 32 itens para melhoria nas indústrias, o planejamento para programação da produção visando a melhor utilização do forno e o planejamento para programação da produção visando melhor cumprimento dos prazos foram melhorias consideradas de importância alta e ocuparam o $4^{\circ}$ e o $6^{\circ}$ lugares, respectivamente, na lista de prioridades.

No problema de planejamento de produção existente em fundições de mercado, o objetivo é determinar um plano de produção que minimize os custos de produção, de preparação, de estoque e de atraso, e que respeite a limitação dos recursos disponíveis. Em outras palavras, devemos determinar o tamanho dos lotes a serem fundidos (produzidos) de cada um dos múltiplos itens da fundição em períodos de tempo de um horizonte de planejamento finito. Isso aborda uma outra decisão fundamental, a escolha das ligas que serão fundidas em cada um dos períodos do horizonte de planejamento.

O objetivo deste trabalho é propor um algoritmo evolutivo capaz de determinar as ligas e as peças a serem fundidas ao longo de um horizonte de planejamento finito utilizando uma heurística lagrangiana como definido em (TONAKI, 2006). Os resultados obtidos com o algoritmo evolutivo são comparados com os resultados da literatura. Além disso, é proposta uma abordagem utilizando o problema de corte unidimensional.

Este trabalho se encontra estruturado da seguinte forma: no Capítulo 2 apresentamos 
a revisão bibliográfica. No Capítulo 3 apresentamos o problema estudado e no Capítulo 4 a abordagem utilizada. No Capítulo 5 propomos o algoritmo evolutivo e descrevemos suas características; os testes computacionais são apresentados no Capítulo 6. Uma outra abordagem de solução para o problema é proposta no Capítulo 7 e os testes computacionais são apresentados no Capítulo 8. Por fim, no Capítulo 9 são apresentadas as conclusões e os trabalhos futuros. 


\section{$2 \quad$ Revisão Bibliográfica}

Segundo Karimi et al. (2003), o problema de dimensionamento de lotes (PDL) é um dos mais importantes e um dos mais difíceis problemas de planejamento da produção. Algumas características que influenciam a modelagem e a complexidade do PDL apresentadas em (KARIMI et al., 2003) são: horizonte de planejamento, número de estágios, número de itens, restrições de capacidade, tipos de demanda, preparação para produção e estoque. Devido ao grande número de classes do PDL, neste trabalho vamos restringir a revisão bibliográfica aos problemas relacionados ao setor de fundições. Para um estudo mais amplo sobre o problema sugerimos os artigos: (BAHL et al., 1986), (MAES et al., 1991), (DREXL; KIMMS, 1997), (WOLSEY, 2002), (KARIMI et al., 2003), (BRAHIMI et al., 2006), (JANS; DEGRAEVE, 2006) e (JANS; DEGRAEVE, 2008).

A grande maioria da produção brasileira de fundidos é consumida pelas indústrias automotivas e siderúrgicas, e é produzida por fundições cativas, que são departamentos dessas grandes empresas. Estas fundições cativas estão orientadas para a produção em série, automatizada e fabricam grandes quantidades de itens que são destinados, basicamente, ao consumo próprio. Assim, a demanda de empresas menores que precisam de produtos fundidos em quantidades pequenas, como, por exemplo, para os setores da indústria mecânica e de infra-estrutura, é atendida por fundições de pequeno e médio porte, que são chamadas fundições de mercado, cuja característica é a venda exclusiva a terceiros. Com demanda relativamente baixa e grande variedade de produtos, as fundições de mercado, geralmente, são marcadas pela ausência de uma política de mercado bem definida e são carentes de uma estrutura gerencial organizada (SILVA; MORABITO, 2004).

Organizamos nossa revisão bibliográfica em três seções, sendo a primeira dedicada às fundições de grande e de médio portes, a segunda é dedicada às fundições de pequeno porte e a terceira à outros trabalhos relacionados à fundições. 


\subsection{Fundições de grande e de médio porte}

Poucos trabalhos que abordam fundições de grande e de médio porte foram encontrados na literatura. Um estudo de caso para uma fundição de grande porte com operação de vários fornos que produzem apenas dois tipos principais de ligas é apresentado em (ARAUJO; ARENALES, 2004a). A programação das linhas de moldagem nesse problema influencia a programação dos fornos. Os autores propõem um modelo matemático e o resolve utilizando um software de programação inteira (CPLEX 7.1). Os resultados computacionais indicam que o modelo matemático proposto representa bem o problema de programação da produção na fundição estudada e sua utilização gera planos de produção que permitem um aumento na produção, de forma a evitar atrasos e a manter o estoque em níveis desejáveis.

VILELA JUNIOR (2007) estuda o problema do planejamento da produção numa fundição de grande porte proposto em (ARAUJO; ARENALES, 2004a) e propõe como método de solução uma heurística lagrangiana baseada no método desenvolvido em (TOLEDO; ARMENTANO, 2006). O autor considera muito bons os resultados obtidos quando comparados à prática.

Santos-Meza et al. (2002) apresentam o problema de sequenciamento e dimensionamento de lotes em uma fundição de médio porte que tem em operação um forno e várias máquinas de moldagem. Os autores expõem duas abordagens para o problema: na primeira abordagem, é necessário fundir somente um tipo de liga para produzir todos os itens demandados; na segunda abordagem é necessário fundir vários tipos de ligas para atender a demanda de itens. Para o primeiro caso, o objetivo é determinar a quantidade de itens produzidos em cada período, respeitando as restrições de capacidade do forno e das máquinas de moldagem, além de balancear a produção dos itens para as diversas máquinas. No segundo caso, uma extensão do primeiro problema foi apresentada de forma que somente os itens que tenham a liga com preparação para produção no período de avaliação possam ser produzidos. Uma heurística foi desenvolvida e os resultados foram comparados com o software comercial CPLEX 4.0. Os autores destacam em seu trabalho a importância do desenvolvimento de métodos heurísticos específicos para resolução de tais problemas.

Em (DUDA; OSYCZKA, 2005) e (DUDA, 2005), os autores abordam de modo semelhante o problema apresentado em (SANTOS-MEZA et al., 2002). Para resolução do modelo são aplicados algoritmos evolutivos multi-objetivo, minimizando o atraso na produção e ma- 
ximizando a utilização das máquinas de moldagem e fornos. Três variações de algoritmos genéticos são testadas e os resultados são comparados com os obtidos por um software comercial.

Em (ARAUJO; ARENALES, 2003), os autores estudam um modelo de dimensionamento de lotes mono-estágio, com restrições de capacidade, máquinas paralelas e múltiplos itens para uma fundição de médio porte, extensões do modelo e do método de solução considerando custo de preparação das máquinas e atrasos na data da entrega foram propostos. Esta abordagem considera um problema prático que ocorre em fundições que têm várias máquinas de moldagem e apenas um forno em operação por período, que é considerado o gargalo do processo produtivo. O método de solução proposto pelos autores é uma heurística composta por três fases. Na primeira fase, a partir da solução da relaxação linear do problema inteiro são determinadas as quantidades produzidas de cada item em cada período. Na segunda fase, com base na solução do problema relaxado uma heurística determina a liga que deve ser produzida em cada período. Finalmente, na terceira fase, é obtida a programação das máquinas de moldagem. Testes computacionais mostram que o método proposto é bastante eficiente.

\subsection{Fundições de pequeno porte}

Em (SILVA; MORABITO, 2004), é estudado o problema de planejamento da produção em uma fundição de pequeno porte que dispõe de vários fornos com restrições de capacidade (máxima e mínima) e possibilidade de funcionamento simultaneamente. É proposta uma abordagem baseada nos problemas de corte e empacotamento (PCE) unidimensionais e como método de solução, uma heurística gulosa para o problema da mochila é considerada para cada combinação possível na utilização dos vários fornos em um dia. O método foi aplicado a um problema com duas semanas de planejamento da produção. Os resultados obtidos foram comparados ao planejamento real de uma fundição de açoinox situada em São Carlos. O planejamento obtido pelo método quando comparado ao planejamento elaborado pela empresa se mostrou mais eficiente, uma vez que reduziu o número de fornadas utilizadas e com isso reduziu o número de dias para a produção dos itens da carteira de pedidos.

Araujo et al. (2004b) abordam o problema de programação da produção de uma fundição de pequeno porte. Neste trabalho é apresentado um modelo matemático para o problema de sequenciamento e dimensionamento de lotes para determinar qual liga será 
fundida em um determinado período e a partir desta liga, quais e quantos itens serão vazados no período com o objetivo de minimizar o atraso para atender a demanda dos itens. Os autores comparam o modelo proposto ao modelo de Drexl e Kimms (1997) e propõem uma extensão do modelo para horizonte de planejamento rolante. São propostos dois métodos de resolução utilizando o software comercial CPLEX 7.1: o primeiro usando busca local e o segundo o método relaxe-e-fixe. A estratégia de horizonte rolante com busca local apresentou os melhores resultados.

Em (ARAUJO et al., 2008), os autores estudam o problema apresentado em (ARAUJO et al., 2004b) e propõem uma melhoria para a heurística de busca local proposta e uma metaheurística simulated annealing. Para a heurística de busca local é proposta uma redução de vizinhança que torna o método mais rápido. As heurísticas propostas são comparadas à heurística relaxe-e-fixe de Araujo et al. (2004b). Os resultados obtidos mostram que a abordagem relaxe-e-fixe obtém as soluções de melhor qualidade, enquanto a busca local é mais rápida. Dentre os três métodos, o simulated annealing obteve as melhores soluções. Os resultados para dados reais de uma fundição mostram que os métodos aplicados além de ajudarem a diminuir consideravelmente o atraso na entrega da demanda, também são capazes de gerar a programação da produção em tempo muito inferior ao que ocorre na prática.

Teixeira.Jr. et al. (2005, 2006a, 2006b), estudaram o problema do planejamento da produção em uma fundição de pequeno porte situada em São Carlos. O problema aborda uma planta com vários reatores e vários fornos; o modelo visa maximizar o lucro na produção sujeito à capacidade dos reatores, dos fornos e da quantidade de 'corridas' dos fornos (fornadas); restritos ao tempo de trabalho no estágio de moldagem e no estágio de acabamento. Os métodos de solução apresentados para esse problema são: um método de programação inteira binária, um modelo heurístico clássico de busca em árvore, conhecido como beam search e uma metaheurística baseada em algoritmos genéticos. Os autores destacam que os métodos de solução propostos geraram bons resultados quando comparados ao limite superior da solução.

Tonaki (2006) e Tonaki e Toledo (2009) estudaram o problema do planejamento da produção em uma fundição de pequeno porte situada em São Carlos. Baseiam-se no modelo do problema desenvolvido por Araujo (2003), que visa minimizar o tempo de atraso na entrega dos itens da carteira de pedidos, em que o gargalo da produção se encontra no forno da fundição. As autoras propõem a decomposição do modelo em dois subproblemas: um problema para as ligas e um problema para as peças. Os subproblemas são resolvidos 
utilizando heurísticas lagrangianas. Foram realizados testes computacionais baseados em cenários e as heurísticas propostas obtiveram resultados melhores que a solução obtida na prática para o valor da função objetivo, no tempo de solução e para a subutilização do forno.

Em (FINK, 2007), são estudados problemas de dimensionamento e sequenciamento de lotes com restrições de capacidade, com múltiplos itens e horizonte de planejamento finito, com possibilidade de atraso no atendimento da demanda e com função objetivo que visa minimizar o atraso na entrega da demanda. Esse trabalho é baseado no problema estudado por (ARAUJO, 2003) e (TONAKI, 2006). O método de solução abordado parte de uma solução encontrada pelos métodos relaxe-e-fixe e busca local para encontrar um boa solução inteira factível do problema para a utilização de uma heurística do tipo residual. Os resultados computacionais mostram que o desempenho da heurística proposta mostrouse inferior ao pacote CPLEX 10.0, entretanto, a diferença entre os gaps da heurística e do CPLEX diminui consideravelmente para problemas maiores.

\subsection{Outras aplicações}

Outras aplicações em fundição podem ser encontradas em (GRAVEL et al., 2000), (LANDMANN, 2005) e (LANDMANN et al., 2006). Em (GRAVEL et al., 2000) é estudado um algoritmo genético de duas fases desenvolvido para o problema de sequenciamento de tarefas para uma fundição com 3 fornos, afim de minimizar o atraso das entregas, minimizar o tempo de preparação no horizonte de planejamento e o fluxo do metal. Os resultados obtidos foram comparados ao método manual utilizado por uma empresa canadense. Os autores reportam que o algoritmo genético encontra rapidamente soluções melhores que o método manual.

Uma programação da produção para o sequenciamento dos moldes em três linhas de moldagem de uma fundição que opera com um único forno é estudada em (LANDMANN, 2005). O objetivo do estudo é maximizar a utilização do forno e minimizar o refugo da produção através da ordenação dos diferentes moldes que utilizam uma única liga. O autor aborda o problema de sequenciamento dos moldes utilizando lógica fuzzy. Em outro trabalho, Landmann et al. (2006) propõem um algoritmo genético como método de solução para o mesmo problema. 


\section{Problema estudado}

A deficiência no planejamento da programação da produção em fundições de pequeno e médio porte foi a motivação para alguns estudos apresentados na literatura ((TONAKI, 2006), (ARAUJO; ARENALES, 2003) e (SILVA; MORABITO, 2004)), assim como para o trabalho aqui proposto. Os trabalhos foram inspirados em uma fundição de pequeno porte situada na cidade de São Carlos que foi utilizada para validar os métodos de solução propostos.

O processo produtivo caracteriza-se por um forno único com limitação de capacidade por fornada, ou seja, a capacidade máxima da liga fundida em cada período é limitada. Após fundida, a liga é vazada em moldes de areia e a sobra é despejada no chão para a formação de lingotes que retornarão para o estoque de matérias-primas e o forno é então realimentado para a produção da próxima liga. Diante disso, observamos que, a programação da produção nesta fundição tem duas fases importantes e dependentes: $a$ programação das ligas, na qual o forno é preparado para a produção de uma liga específica; e a programação das peças, na qual é definida a quantidade de cada item (peça) a ser produzida a partir das ligas fundidas, ou seja, devemos dimensionar os lotes de cada item.

O gargalo de produção para a fundição em questão é o forno. Logo, é abordado um problema de planejamento de produção de múltiplos itens com único estágio de produção. O objetivo é encontrar o plano de produção que minimize os custos de atraso, de estoque e de preparação. O horizonte de planejamento é finito e subdividido em períodos menores. A capacidade de produção nos períodos é limitada pela capacidade do forno e a demanda pelos itens é previamente determinada. O plano de produção deve respeitar a capacidade de produção. Em cada um dos períodos deve ser determinada a liga metálica a ser fundida, logo, apenas os itens feitos a partir da liga fundida podem ser produzidos. Este problema pertence à área de otimização combinatória e Araujo (2003) propuseram o seguinte modelo de programação inteira mista para sua representação:

\section{Índices:}


- $k=1, \ldots, K$ : tipos de ligas;

- $i=1, \ldots, N$ : tipos de itens;

- $t=1, \ldots, T$ : períodos de tempo (dias, por exemplo);

- $F_{t}=1+\sum_{j=1}^{t-1} \eta_{j}$ : primeiro subperíodo no dia $t$;

- $L_{t}=F_{t}+\eta_{t}-1$ : último subperíodo no dia $t$;

- $\eta=\sum_{t=1}^{T} \eta_{t}$ : número total de subperíodos no horizonte de planejamento.

\section{Dados do problema:}

- $\eta_{t}$ : número de fornadas no dia (período) $t$;

- Cap: capacidade do forno $(\mathrm{kg})$;

- $\rho_{i}$ : peso bruto $(\mathrm{kg})$ do item $i$;

- $d_{i t}$ : demanda do item $i$ no período $t$;

- $H_{i t}^{-}$: penalidade pelo atraso na entrega de uma unidade do item $i$ no período $t$;

- $H_{i t}^{+}$: penalidade por antecipação de uma unidade do item $i$ no período $t$;

- $S(k)$ : conjunto de itens $i$ que usam a liga $k$ (cada item utiliza um, e somente um tipo de liga, ou seja: $\{1, \ldots, N\} \subset S(1) \cup \ldots \cup S(k), S(h) \cap S(j)=\emptyset, \forall h \neq j)$;

- $s_{k}$ : penalidade pela preparação da liga $k$.

\section{Variáveis do problema:}

- $X_{i n}$ : quantidade produzida do item $i$ no subperíodo $n$;

- $I_{i t}^{-}$: quantidade atrasada do item $i$ no final do período $t$,

- $I_{i t}^{+}$: quantidade estocada do item $i$ no final do período $t$.

- $Y_{n}^{k}$ : variável binária $\left(Y_{n}^{k}=1\right.$ indica que o forno é preparado para produzir a liga $k$ no subperíodo $n$, caso contrário, $\left.Y_{n}^{k}=0\right)$. 
- $Z_{n}^{k}$ : variável que indica se é cobrado a penalidade pela preparação da liga $k$ no subperíodo $n$ : $Z_{n}^{k}=0$ se $Y_{n-1}^{k} \geq Y_{n}^{k}$ e $Z_{n}^{k}=1$, caso contrário. Embora esta variável seja binária em essência, pode ser modelada como contínua.

\section{Modelo Matemático:}

$$
\operatorname{Minimizar} \sum_{i=1}^{N} \sum_{t=1}^{T}\left(H_{i t}^{-} I_{i t}^{-}+H_{i t}^{+} I_{i t}^{+}\right)+\sum_{k=1}^{K} \sum_{n=F_{1}}^{L_{T}}\left(s_{k} Z_{n}^{k}\right)
$$

$$
\begin{aligned}
& \text { Sujeito a: } \quad I_{i, t-1}^{+}-I_{i, t-1}^{-}+\sum_{n=F_{t}}^{L_{t}} X_{i n}-I_{i t}^{+}+I_{i t}^{-}=d_{i t} \quad i=1, \ldots, N ; \quad t=1, \ldots, T ; \\
& \sum_{i \in S(k)} \rho_{i} X_{i n} \leq \operatorname{CapY}_{n}^{k} \quad k=1, \ldots, K ; \quad n=F_{1}, \ldots, L_{T} ; \\
& Z_{n}^{k} \geq Y_{n}^{k}-Y_{n-1}^{k} \quad k=1, \ldots, K ; \quad n=F_{1}, \ldots, L_{T} ; \\
& \sum_{k=1}^{K} Y_{n}^{k}=1 \\
& n=F_{1}, \ldots, L_{T} ; \\
& Z_{n}^{k}, Y_{n}^{k} \in\{1,0\}\left(Y_{0}^{k}=0\right) \\
& k=1, \ldots, K ; \quad n=F_{1}, \ldots, L_{T} ; \\
& X_{\text {in }} \geq 0 \text { inteira } \\
& i=1, \ldots, N \text {; } \\
& n=F_{1}, \ldots, L_{T} \text {; } \\
& I_{i t}^{+} \text {e } I_{i t}^{-} \geq 0\left(I_{i 0}^{+} \text {e } I_{i 0}^{-}=0\right) \\
& i=1, \ldots, N ; \quad t=0, \ldots, T \text {. }
\end{aligned}
$$

A função objetivo (3.1) consiste em minimizar os atrasos na entrega dos pedidos. Penalidades são associadas ao atraso e antecipação da produção e para a preparação das ligas. As restrições (3.2) representam as equações de balanço de estoque. Em (3.3), a produção de todos os itens é limitada à capacidade do forno e asseguram que os itens que utilizam determinada liga só podem ser produzidos quando essa liga for preparada. Mudanças de ligas são representadas pelas restrições (3.4). As restrições (3.5) garantem que apenas uma liga pode ser produzida em cada subperíodo. As restrições (3.6) - (3.8) garantem a não-negatividade das variáveis, a integralidade das variáveis $Z_{n}^{k}, Y_{n}^{k}$ e $X_{i n}$ e supõe, sem perda de generalidade, que os estoques iniciais são nulos. 


\section{Abordagem utilizada}

Com base no modelo apresentado por (ARAUJO, 2003), Tonaki (2006) propôs resolver o problema em duas etapas, primeiro planejar a quantidade de fornadas de cada liga que deve ser fundida e em seguida planejar a quantidade de itens. Para tanto, a autora deveria determinar a quantidade de fornadas necessária de cada liga para produzir os itens com demanda em cada período $t$.

Considerando a equação de balanceamento de estoque (3.2) e multiplicando cada termo pela constante de peso de cada item $i\left(\rho_{i}\right)$, temos a demanda em peso para cada item $i$ :

$$
\rho_{i} I_{i, t-1}^{+}-\rho_{i} I_{i, t-1}^{-}+\sum_{n=F_{t}}^{L_{t}} \rho_{i} X_{i n}-\rho_{i} I_{i t}^{+}+\rho_{i} I_{i t}^{-}=\rho_{i} d_{i t} \quad i=1, \ldots, N ; \quad t=1, \ldots, T .
$$

Dado que $S(k)$ é o conjunto de itens produzidos utilizando a liga $k$, a equação de balanceamento de estoque para uma liga $k$ pode ser obtida de (4.1) pela soma dos itens pertencentes à $S(k)$ :

$$
\begin{array}{rl}
\sum_{i \in S(k)} \rho_{i} I_{i, t-1}^{+}-\sum_{i \in S(k)} \rho_{i} I_{i, t-1}^{-}+\sum_{i \in S(k)} \sum_{n=F_{t}}^{L_{t}} \rho_{i} X_{i n}-\sum_{i \in S(k)} \rho_{i} I_{i t}^{+}+\sum_{i \in S(k)} \rho_{i} I_{i t}^{-}=\sum_{i \in S(k)} \rho_{i} d_{i t} & i=1, \ldots, N ; \quad t=1, \ldots, T .
\end{array}
$$

Reescrevendo a restrição (4.2):

$$
E_{k, t-1}^{+}-E_{k, t-1}^{-}+\sum_{i \in S(k)} \sum_{n=F_{t}}^{L_{t}} \rho_{i} X_{i n}-E_{k t}^{+}+E_{k t}^{-}=D_{k t} \quad k=1, \ldots, K ; \quad t=1, \ldots, T
$$

em que:

$E_{k, t}^{-}$: quantidade atrasada da liga $k(\mathrm{em} \mathrm{kg})$ no período $t$;

$E_{k, t}^{+}$: quantidade estocada da liga $k(\mathrm{em} \mathrm{kg}$ ) no período $t$;

$D_{k, t}$ : demanda da liga $k$ no período $t$.

Na equação (4.3), $\sum_{i \in S(k)} \sum_{n=F_{t}}^{L_{t}} \rho_{i} X_{i n}$ representa o total em quilos da liga $k$ produzido no período $t$. Definindo $A_{k, t}$ como o número de vezes em que a liga $k$ é fundida no 
período $t$ e uma vez que fundida a liga, esta pode ocupar a capacidade máxima do forno, temos:

$$
E_{k, t-1}^{+}-E_{k, t-1}^{-}+\operatorname{Cap} A_{k, t}-E_{k, t}^{+}+E_{k, t}^{-}=D_{k, t} \quad k=1, \ldots, K ; \quad t=1, \ldots, T .
$$

Devemos garantir que o número de fornadas no período $t$ respeite o limite de cargas do forno:

$$
\sum_{k=1}^{K} A_{k, t} \leq \eta_{t} \quad t=1, \ldots, T
$$

além disso, sempre que uma liga é fundida, é necessário que haja preparação do forno, $\log \mathrm{O}$

$$
A_{k, t} \leq \eta_{t} \bar{Y}_{t}^{k} \quad k=1, \ldots, K ; \quad t=1, \ldots, T
$$

em que:

$\bar{Y}_{t}^{k}$ : variável binária $\left(\bar{Y}_{t}^{k}=1\right.$ indica que o forno é preparado para produzir a liga $k$ no período $t$, caso contrário, $\left.\bar{Y}_{t}^{k}=0\right)$.

A seguir, definimos os dados do problema das ligas:

- $H_{k, t}^{-}$: penalidade pelo atraso na entrega de $1 \mathrm{~kg}$ da liga $k$ no período $t$;

- $H_{k, t}^{+}$: penalidade por antecipação de $1 \mathrm{~kg}$ da liga $k$ no período $t$;

- $s_{k}$ : penalidade pela preparação da liga $k$.

Desta forma o modelo para as ligas pode ser rescrito como:

\section{Modelo Matemático das Ligas:}

\section{Minimizar}

$$
\sum_{t l=1}^{T l} \sum_{k=1}^{K}\left(H_{k, t l}^{-} E_{k, t l}^{-}+H_{k, t l}^{+} E_{k, t l}^{+}+s_{k} \bar{Y}_{t}^{k}\right)
$$

\section{Sujeito a:}

$$
\begin{array}{lll}
E_{k, t-1}^{+}-E_{k, t-1}^{-}+\operatorname{Cap}_{k, t}-E_{k, t}^{+}+E_{k, t}^{-}=D_{k, t} & k=1, \ldots, K ; & t=1, \ldots, T ; \\
\sum_{k=1}^{K} A_{k, t} \leq \eta_{t} & t=1, \ldots, T ; & \\
A_{k, t} \leq \eta_{t} \bar{Y}_{t}^{k} & k=1, \ldots, K ; & t=1, \ldots, T ; \\
\bar{Y}_{t}^{k} \in\{0,1\} & k=1, \ldots, K ; & t=1, \ldots, T ; \\
A_{k, t} \geq 0, \text { inteira } & k=1, \ldots, K ; & t=1, \ldots, T ; \\
E_{k, t}^{+} \text {e } E_{k, t}^{-} \geq 0\left(E_{k, 0}^{+} \text {e } E_{k, 0}^{-}=0\right) & k=1, \ldots, K ; & t=0, \ldots, T .
\end{array}
$$


A função objetivo (4.7) busca minimizar os custos de atraso, de estoque e de preparação. As equações (4.4) são as restrições de balanceamento de estoque. As restrições (4.5) limitam o número de fornadas em um período de trabalho em $\eta_{t}$. As restrições (4.6) asseguram que uma liga só será fundida caso haja sua preparação. As restrições (4.8) definem $\bar{Y}_{t}^{k}$ como variável binária, as restrições (4.9) representam as condições de não-negatividade da variável inteira $A_{k, t}$ e por fim, as restrições (4.10) representam as condições de não-negatividade das variáveis $E_{k, t}^{-}$e $E_{k, t}^{+}$.

Uma vez determinadas as ligas que serão fundidas no período $\left(\bar{Y}_{t}^{k}\right)$, podemos determinar os subperíodos em que as ligas são preparadas $\left(Y_{n}^{k}\right)$, que passa a ser um parâmetro para o problema de dimensionamento de lote para os itens. O problema de planejamento dos itens (peças) pode ser decomposto em $K$ subproblemas de dimensionamento de lotes independentes, um para cada liga. O problema das peças é apresentado a seguir.

Modelo Matemático das Peças $P_{k}, k=1, \ldots, K$ :

Minimizar

$$
\sum_{t=1}^{T} \sum_{i \in S(k)}\left(H_{i, t}^{-} I_{i, t}^{-}+H_{i, t}^{+} I_{i, t}^{+}\right)
$$

\section{Sujeito a:}

$$
\begin{array}{lll}
I_{i, t-1}^{+}-I_{i, t-1}^{-}+\sum_{n=F_{t}}^{L_{t}} X_{i n}-I_{i t}^{+}+I_{i t}^{-}=d_{i t} & \forall i \in S(k) ; & t=1, \ldots, T ; \\
\sum_{i \in S(k)} \rho_{i} X_{i n} \leq C a p Y_{n}^{k} & k=1, \ldots, K ; & n=F_{1}, \ldots, L_{T} ; \\
X_{i n} \geq 0, \quad \text { inteira } & \forall i \in S(k) ; & n=F_{1}, \ldots, L_{T} ; \\
I_{i t}^{+} e I_{i t}^{-} \geq 0\left(I_{i 0}^{+} \text {e } I_{i 0}^{-}=0\right) & \forall i \in S(k) ; \quad t=0, \ldots, T .
\end{array}
$$

A função objetivo (4.11) busca minimizar custos de atraso e de estoque dos itens da carteira de pedido. As restrições (4.12) são de balanceamento de estoque e as restrições (4.13) asseguram que itens que utilizam determinada liga só poderão ser produzidos neste subperíodo se a liga for fundida no mesmo subperíodo e com quantidade restrita à capacidade do forno. As restrições (4.14) representam as condições de não-negatividade da variável inteira $X_{i, n}$ e, por fim, as restrições (4.15) representam as condições de nãonegatividade das variáveis $I_{i, t}^{-}$e $I_{i, t}^{+}$. 


\section{Método proposto}

Para o modelo decomposto apresentado em (TONAKI, 2006), a autora propõe um método baseado em heurísticas lagrangianas para solução do problema. A autora destaca que, uma vez determinadas as ligas, o subproblema das peças é resolvido com eficiência. Testes comparando os resultados obtidos pela heurística quando aplicada para determinar as peças e a solução para o mesmo problema das peças obtida por um pacote de otimização mostraram resultados muito semelhantes. No entanto, o subproblema que determina as ligas ainda poderia ser melhorado.

Neste trabalho propomos um algoritmo genético (para detalhes, ver (HOLLAND, 1992), (GOLDBERG, 1989), (SRINIVAS; PATNAIK, 1994), (MAN et al., 1996) e (SAIT; YOUSSEF, 1999)) para solução do problema. A ideia geral do algoritmo é baseada na decomposição do problema proposta em (TONAKI, 2006). Cada cromossomo representa todas as ligas fundidas ao longo do horizonte de planejamento, logo, testamos diferentes possibilidades de planejamento para as ligas. Uma vez determinadas as ligas, a avaliação do cromossomo é obtida resolvendo o problema das peças utilizando o algoritmo baseado em relaxação lagrangiana proposto por (TONAKI, 2006). A metaheurística proposta é ilustrada no Algoritmo 1 e seus passos são detalhados a seguir.

Gere uma população inicial;

Avaliação da população utilizando a heurística lagrangiana de Tonaki (2006);

Enquanto critério de parada não for satisfeito faça

Seleção;

Crossover;

Mutação;

Avaliação da população;

Fim enquanto

Retorne a melhor solução encontrada;

Algoritmo 1: Algoritmo da metaheurística proposta. 


\subsection{Codificação do cromossomo}

A representação de uma solução do problema como um cromossomo foi determinada de modo que a codificação contenha o menor conjunto de soluções possíveis na representação. Desta forma, estudamos três possibilidades de codificação do cromossomo. É importante ressaltar que para o problema estudado, $K$ representa o número total de ligas na carteira de pedidos, $T l$ são os dias de programação no horizonte de planejamento e $L$ é o número de fornadas possíveis por dia de programação, ou seja, o número máximo de ligas que podem ser fundidas em um dia de programação.

Na primeira codificação, a dupla (fornadas, período) foi associado à um vetor com $K$ dígitos 0 ou 1, em que, apenas um deles assume o valor 1 e representa a liga fundida na dupla (fornadas, período). A Figura 1 ilustra um esquema da primeira representação que tem codificação binária, em que, são representadas todas as ligas para todas as fornadas em todos os períodos. O cromossomo é constituído por $(K * T l * L)$ genes, em que, os valores 0 e 1 são admitidos, constituindo um conjunto de $2^{(K * T l * L)}$ possíveis soluções.
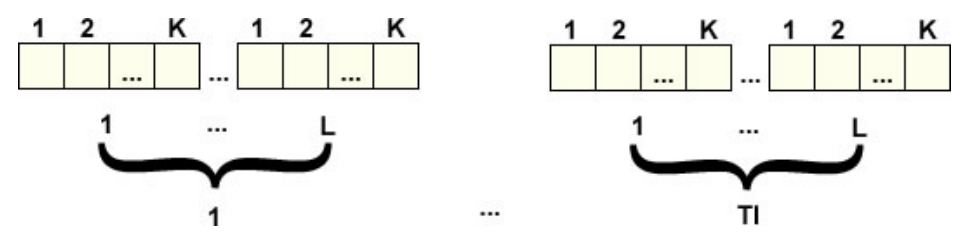

Figura 1: Esquema da representação binária do cromossomo.

Ilustramos na Figura 2 o esquema da segunda representação que codifica todas as ligas para todos os períodos, em que, cada elemento do cromossomo representa a quantidade de vezes que a liga é fundida em cada período, esse valor pode ser no máximo $L$, respeitando a capacidade de produção do forno. O cromossomo seria constituído por $(K * T l)$ genes, podendo assumir valores entre 0 e $L$, constituindo um conjunto de $(L+1)^{(K * T l)}$ possíveis soluções.

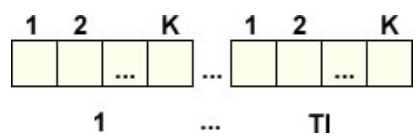

Figura 2: Esquema da segunda representação do cromossomo.

Finalmente, ilustramos na Figura 3 o esquema da terceira representação na qual são associadas as duplas (fornadas, período). Representamos quais ligas serão fundidas em cada fornada de cada período, assim é representada a sequência de produção das ligas. Desta forma, o cromossomo seria constituído por $(L * T l)$ genes. Cada gene tem o valor 
que representa a liga que é fundida, assim, os valores associados às ligas são $[1 ; K]$ e 0 representa que nenhuma liga seria fundida. Esta representação constitui de um conjunto de $(K+1)^{(L * T l)}$ soluções possíveis.

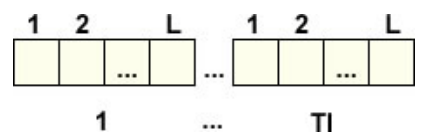

Figura 3: Esquema da terceira representação do cromossomo.

Como exemplo para o cálculo do conjunto de soluções possíveis, determinamos o número de dias no horizonte de planejamento $T l=5$ e o número de fornadas possíveis por dia $L=10$. Assim, como apresentamos na Tabela 1, o menor conjunto de soluções é gerado pela terceira representação para $K>10$, ou seja, para mais de 10 ligas na carteira de pedidos, o que é comum na prática.

Tabela 1: Exemplo do cálculo do conjunto de soluções possíveis.

\begin{tabular}{l|ccc}
\hline & $1^{a}$ representação & $2^{a}$ representação & $3^{a}$ representação \\
\hline$K$ & $2^{(K * T l * L)}$ & $(L+1)^{(K * T l)}$ & $(K+1)^{(T l * L)}$ \\
\hline 1 & $2^{50}$ & $11^{5}$ & 1 \\
5 & $2^{250}$ & $11^{25}$ & $6^{50}$ \\
10 & $2^{500}$ & $11^{50}$ & $11^{50}$ \\
15 & $2^{750}$ & $11^{75}$ & $16^{50}$ \\
20 & $2^{1000}$ & $11^{100}$ & $21^{50}$ \\
\hline
\end{tabular}

É certo que a primeira representação pode gerar um conjunto de soluções tão pequeno quanto a terceira, porém, seria necessário um tratamento dos dados durante a execução dos processos do algoritmo genético, pois dos $(K * T l * L)$ genes existentes no cromossomo, no máximo $(T l * L)$ genes com valor 1 são representativos, em outras palavras, é necessário respeitar o número máximo de fornadas nos $T l$ dias de planejamento.

Dentre os 3 tipos de codificações pesquisadas, escolhemos utilizar a terceira possibilidade estudada, que representa quais ligas são fundidas em cada fornada de cada período, ou seja, representa a sequência de produção das ligas. Esta representação é, dentre todas as estudadas, a que possui o menor conjunto de soluções possíveis para o problema sem que haja necessidade de tratamento dos valores dos genes. Com a codificação definida, o cromossomo é constituído por $(L * T l)$ genes, em que, $L$ é a quantidade total de fornadas em um dia e $T l$ é a quantidade de dias do horizonte de planejamento. O número de soluções possíveis desta representação é de $(K+1)^{(L * T l)}$, em que, $K$ é o número de ligas presentes na carteira de pedido. 


\subsection{População inicial}

A população inicial de soluções foi gerada de três maneiras: aleatoriamente, utilizando a relaxação linear do problema completo apresentado no Capítulo 3 e usando uma heurística pseudo-gulosa.

Na primeira forma de geração, cada gene do cromossomo é composto por um número entre 0 e $K$ determinado aleatoriamente que indica qual liga é fundida em cada fornada de cada período (que chamamos de subperíodo), em que, 0 representa que nenhuma liga é fundida.

$\mathrm{Na}$ segunda forma, resolvemos a relaxação linear do modelo proposto por Araujo (2003) para obter os valores de $Y_{t}^{k}$ relaxados. Com esses dados, para cada subperíodo $t$ construímos uma roleta para as $K$ ligas com $Y_{t}^{k}>0$. Por exemplo, a roleta no subperíodo

$t=1$ tem tamanho $\sum_{k=1}^{K} Y_{t}^{k}$, logo, sorteamos um número entre 0 e $\sum_{k=1}^{K} Y_{t}^{k}$ que define a liga $k$ para o gene $t$ do cromossomo. Esse procedimento é repetido para todos os cromossomos gerados.

$\mathrm{Na}$ terceira forma, criamos uma lista de ligas candidatas ordenada de forma que as ligas com maior demanda em peso atrasada e, posteriormente, as ligas com maior demanda em peso em carteira (demanda não atrasada) possam ter maior probabilidade de serem escolhidas. Da lista ordenada, uma liga selecionada aleatoriamente entre as 10 primeiras é transcrita para o primeiro gene do cromossomo, e eliminada da lista. Esta operação é realizada para todos os genes do indivíduo.

Testes preliminares mostraram que a terceira forma de geração da população inicial apresentada, utilizando uma lista de ligas candidatas, constrói indivíduos melhores adaptados e que auxiliam na evolução.

\subsection{Cruzamento}

Este operador tem a função de transmitir as características dos bons indivíduos aos descendentes. Para o problema estudado, os indivíduos com menores custos são considerados melhores. Nossa proposta de cruzamento busca transmitir às gerações futuras os planos de produção das ligas que gerem menores custos de atraso e de estoque.

Para este operador que constrói as novas gerações estudamos dois tipos de cruzamento: No primeiro, selecionamos dois indivíduos aleatoriamente e determinamos que 
o descendente gerado (Figura 4a) dessa operação terá genes com $70 \%$ de chance de ser do indivíduo com melhor valor de avaliação (Figura 4b) e 30\% de chance de ser do pior (Figura 4c), ou seja, bit-a-bit determinamos de qual indivíduo o gene seria copiado com probabilidade maior para o indivíduo mais adaptado ao problema. Ilustramos na Figura 4 um exemplo deste cruzamento proposto.

(b)

(c)

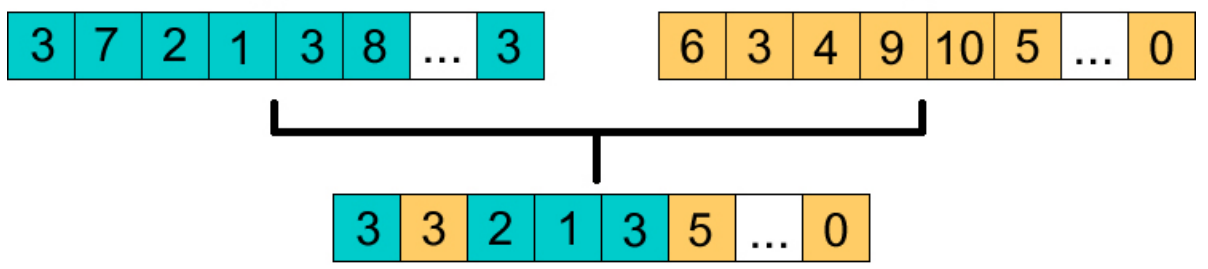

(a)

Figura 4: Esquema do primeiro cruzamento proposto.

Para o segundo tipo de cruzamento estudado, a cada indivíduo está associado um vetor com os custos que cada liga contribui na avaliação da solução, assim, podemos comparar se uma liga está melhor planejada em um indivíduo ou em outro. Para gerar descendentes por cruzamento, dois indivíduos são selecionados aleatoriamente na população e, dentre os dois é escolhido o melhor para ser base para o cruzamento ao qual chamamos de pai-base. Fazemos a comparação gene-a-gene a partir do pai-base, ou seja, comparamos o custo da liga do primeiro gene do pai-base (Figura 5a) com o custo da mesma liga do outro pai (Figura 5b). Se o custo da liga no pai-base for menor, o plano de produção para esta liga é transmitido aos mesmos genes do descendente gerado (Figura 5c), caso contrário, a liga do primeiro gene do outro pai é transmitida. Esta comparação é feita gene-a-gene para os $(L * T l)$ genes em que houver uma lacuna no descendente. Ilustramos na Figura 5 um exemplo do cruzamento baseado nos custos de cada liga.

(a)

(b)

\begin{tabular}{|l|l|l|l|l|l|l|l|l|l|l|l|l|l|l|l|}
\hline 3 & 7 & 2 & 1 & 3 & 8 & $\ldots$ & 3 \\
1
\end{tabular}

Figura 5: Esquema do segundo cruzamento proposto.

Pelo cruzamento adotado geramos o mesmo número de descendentes que o tamanho da população. 
Teste preliminares mostraram que o cruzamento baseado no planejamento da produção de cada liga transmite melhor as características dos indivíduos às gerações seguintes.

\subsection{Mutação}

A operação de mutação tem como finalidade manter a diversidade na população, regenerando o material genético perdido durante as gerações ou ainda, explorando uma genética diferente nunca presente na população.

Segundo (SAIT; YOUSSEF, 1999), cada gene de cada indivíduo tem uma pequena chance de sofrer mutação. Larranaga e Lozano (2001) apontam que muitos pesquisadores utilizam valores pequenos para a taxa de mutação, tal como $1 / n$, em que, $n$ é o número de genes do cromossomo.

Outra proposta é aplicar uma taxa individual de mutação. Cada indivíduo tem um probabilidade de ter mutação em seus genes. Se houver mutação, 1, 2 ou 3 genes podem sofrer alteração com uma certa probabilidade.

Neste trabalho, a mutação de um gene compreende que uma liga selecionada aleatoriamente é alocada ao gene, diversificando e explorando novas combinações de ligas na programação.

\subsection{Mecanismo de seleção}

Este mecanismo tem a função de selecionar quais indivíduos vão compor a população na próxima geração. Duas estratégias foram estudadas. A primeira com o intuito de garantir a sobrevivência somente dos melhores indivíduos, é proposto o elitismo entre a população e seus descendentes. Dentre todos os indivíduos os melhores sobrevivem à geração seguinte e no mínimo dois melhores indivíduos dos descendentes sobreviverão independente do valor da função de avaliação, afim de manter diversidade na população evoluída.

Na segunda estratégia, é proposto um estágio de maturação para os descendentes, ou seja, o elitismo é aplicado entre a população e seus descendentes, porém, os descendentes passam pelo mecanismo de seleção somente após atingirem um tempo de maturação. O tempo de maturação é o número de gerações que o indivíduo descendente permanece inativo antes de fazer parte da população e é outro parâmetro a ser definido no algoritmo 
genético. O propósito dessa estratégia é evitar que a população tenha uma convergência prematura.

Testes indicaram que a estratégia com estágio de maturação teve bom desempenho em cenários considerados difíceis, porém de modo geral, a primeira estratégia obtém o melhor resultado final independente do cenário.

\subsection{Avaliação do indivíduo}

A avaliação dos indivíduos é o mecanismo que determina quão boa é a solução comparada ao resto da população. Cada indivíduo carrega a sequência de ligas para produção no horizonte de planejamento, é necessário então, determinar os lotes que minimizam a função objetivo do problema das peças como definido por Tonaki (2006). A função de avaliação mostra quanto um indivíduo está adaptado ao ambiente, qual é o custo de atraso, de estoque e de preparação do indivíduo.

Utilizamos o método desenvolvido por Tonaki (2006) para o cálculo da função de avaliação. Por construção, podemos garantir a factibilidade da população que contém os indivíduos representando a sequência das ligas que serão fundidas no horizonte de planejamento. Para cada liga fundida podemos determinar com eficiência através da heurística lagrangiana (HL) quais peças serão produzidos em cada período.

A heurística lagrangiana nos fornece o valor da função objetivo para os $K$ problemas das peças, logo, o valor da função de avaliação é a soma dos valores das $K$ funções objetivo e os custos de preparação para as ligas fundidas $\left(\sum_{k=1}^{K} \sum_{t=1}^{T} s_{k} \bar{Y}_{t}^{k}\right)$.

Abaixo, são ilustrados os passos da heurística que são detalhados nas próximas seções.

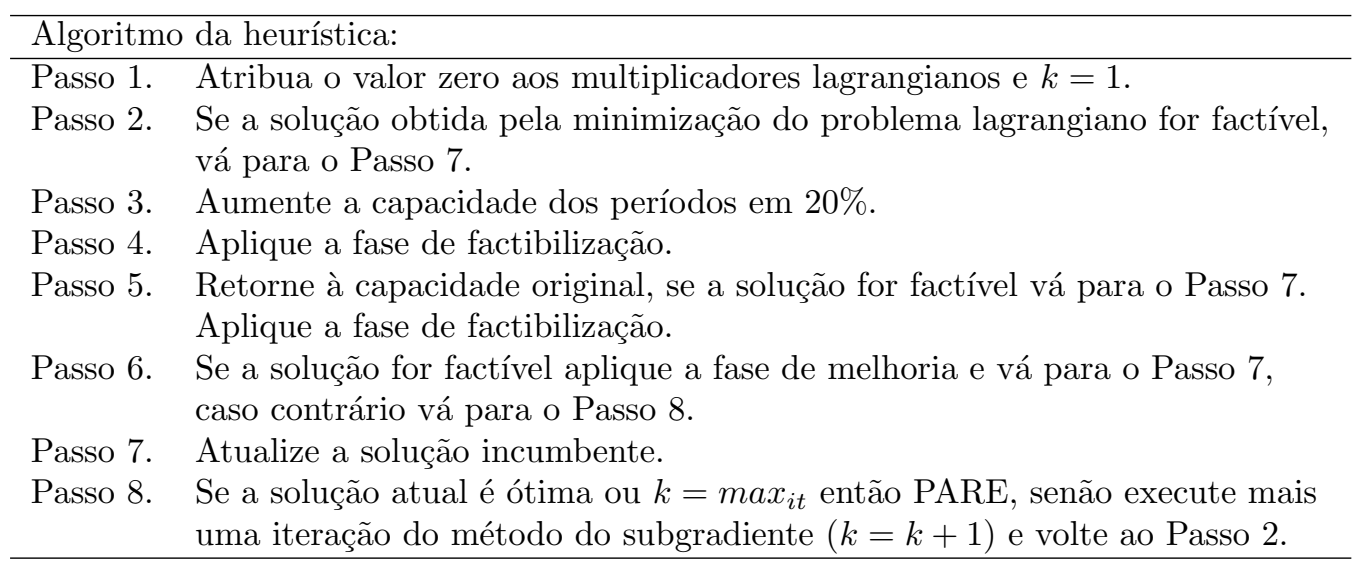




\subsubsection{Relaxação lagrangiana}

Dada a relaxação lagrangiana das restrições de capacidade (4.13) e sejam $\mu_{t} \geq 0, t=$ $1, \ldots, T$, os multiplicadores lagrangianos relacionados, o problema lagrangiano para o problema das peças é dado por:

$g\left(\mu_{t}\right)=$ Minimizar

$$
\sum_{t=1}^{T} \sum_{i \in S(k)}\left(H_{i, t}^{-} I_{i, t}^{-}+H_{i, t}^{+} I_{i, t}^{+}\right)+\sum_{t=1}^{T} \mu_{t}\left(\sum_{i \in S(k)} \rho_{i} X_{i t}-\operatorname{Cap}_{t}^{k}\right)
$$

Sujeito a: (4.12), (4.14) e (4.15).

O problema $g\left(\mu_{t}\right)$ pode ser decomposto em $i(i \in S(k))$ subproblemas independentes, um para cada peça do conjunto $S$ da liga $k$, como apresentado a seguir:

$g_{i}\left(\mu_{t}\right)=$ Minimizar

$$
\sum_{t=1}^{T}\left(H_{i, t}^{-} I_{i, t}^{-}+H_{i, t}^{+} I_{i, t}^{+}+\mu_{t} \rho_{i} X_{i t}\right)
$$

Sujeito a:

$$
\begin{array}{ll}
I_{i, t-1}^{+}-I_{i, t-1}^{-}+X_{i t}-I_{i t}^{+}+I_{i t}^{-}=d_{i t} & t=1, \ldots, T ; \\
X_{i t} \geq 0, \quad \text { inteira } & t=0, \ldots, T ; \\
I_{i t}^{+} \text {e } I_{i t}^{-} \geq 0\left(I_{i 0}^{+}=I_{i 0}^{-}=0\right) & t=0, \ldots, T .
\end{array}
$$

Cada um dos subproblemas é um problema de dimensionamento de lotes não capacitado, com atraso de demanda permitido. Somente pode haver produção nos períodos onde há preparação para a liga $k$, ou seja, $Y_{t}^{k}=1$. Estes subproblemas podem ser resolvidos na otimalidade pelo algoritmo de programação dinâmica proposto em (ZANGWILL, 1969). Para que fosse retratada a produção nos períodos onde há preparação da liga, a autora aplicou um custo de preparação para cada período $t$ com valor zero nos períodos onde há preparação para a liga e infinito nos períodos sem preparação.

O método do subgradiente foi utilizado para maximizar a função dual $g\left(\mu_{t}\right)$ com $\mu_{t} \geq 0, t=1, \ldots, T$. 


\subsubsection{Heurística lagrangiana}

A heurística lagrangiana proposta por Tonaki (2006) é composta por três fases: obtenção da solução inicial, factibilização e melhoria que são descritas a seguir.

A partir da solução obtida pelo problema de minimização lagrangiano, se infactível para o problema capacitado, a fase de factibilização transfere a produção entre os períodos em que há preparação para a liga na tentativa de encontrar uma solução factível para o problema com capacidade aumentada em $20 \%$ com a finalidade de distribuir o excesso da produção entre os períodos; se a solução resultante não é factível, a capacidade original é retomada e a fase de factibilização é aplicada novamente. A partir de uma solução factível proveniente da fase de factibilização, a fase de melhoria procura por soluções com custos menores.

\section{Fase de factibilização}

Se a solução inicial não é factível em relação às restrições relaxadas, isto é, a capacidade do forno é excedida em um ou mais períodos, tenta-se construir uma solução factível através da transferência da produção de itens de períodos com capacidade excedida para outros períodos. Esta fase consiste de um passo regressivo, que tenta transferir a capacidade excedida dos últimos períodos para os primeiro, e um passo progressivo, que realiza o mesmo procedimento na ordem inversa. Tem-se ao final dessa fase um solução factível para o problema, pois ao final da execução, a produção excedida no último período é eliminada do planejamento tornando-se atraso de produção.

\section{Fase de melhoria}

A partir da solução factível, a fase de melhoria tenta reduzir o custo total da solução sempre respeitando a factibilidade, transferindo a produção de peças entre os períodos em que há preparação da liga e, assim, diminuir o estoque nos períodos. Esta fase consiste de um passo regressivo, que tenta transferir a produção de alguma quantidade de peças dos últimos períodos para os primeiro, e um passo progressivo, que realiza o mesmo procedimento na ordem inversa.

\subsection{Estrutura de árvore}

Testes realizados com uma carteira de pedidos composta por 383 peças, 19 tipos de ligas e 5 dias de planejamento mostraram que o método da heurística lagrangiana realiza a avaliação de um indivíduo em aproximadamente 60 segundos. Para uma população 
com 10 indivíduos e critério de parada de 200 gerações, seriam gastos aproximadamente 120.000 segundos para avaliação dos indivíduos na execução do algoritmo genético.

Sabemos que dado o vetor de preparações $Y_{t}^{k}, \forall t$, a heurística lagrangiana resolve de forma independente o subproblema para cada uma das $k$ ligas. Assim, como forma de reduzir o tempo gasto na avaliação dos indivíduos, implementamos uma estrutura de dados em árvore, em que as folhas guardam a avaliação para uma determinada liga produzida segundo um dado planejamento, ou seja, valores de $Y_{t}^{k}$ para um dado $k$. Por exemplo, a liga 5 é fundida 1 vez no primeiro dia, 2 vezes no segundo dia e nenhuma vez nos outros 3 dias, o valor da avaliação da liga 5 para esta configuração de preparações será armazenado no endereço $[5,1,2,0,0,0]$. A ideia é reaproveitar o cálculo de um planejamento já computado.

Em um cenário com horizonte de planejamento de 5 dias, a árvore conterá 6 níveis, ou seja, o número de dias mais um, em que o endereço no primeiro nível é determinado pelo número liga, o endereço no segundo nível é o número de vezes que esta liga é fundida no primeiro dia, o endereço no terceiro nível é o número de vezes que esta liga é fundida no segundo dia, assim por diante.

Com esta estratégia, para uma população com 10 indivíduos e critério de parada de 200 gerações o tempo gasto pelo método é inferior à 10.000 segundos.

\subsection{Busca local}

Segundo Sait e Youssef (1999), a heurística de busca local é um dos mais antigos e fáceis métodos de otimização e, tem sido aplicada com sucesso à vários problemas difíceis de otimização combinatória. A estratégia de um algoritmo de busca local é, a partir de uma solução factível inicial, buscar por soluções melhores na sua vizinhança usando uma subrotina de melhoria. Se uma solução melhor é encontrada, a busca continua na vizinhança dessa nova solução. O algoritmo para quando atinge um ótimo local. A subrotina de melhoria pode ser aplicada com duas estratégias: a estratégia de primeira melhoria, quando a primeira solução de menor custo é encontrada, a solução é aceita; ou a estratégia de máxima descida, em que a vizinhança inteira é investigada e a solução de menor custo é aceita.

A aplicação de uma busca local foi estudada afim de melhorar os resultados obtidos pelo método proposto. Nessa estratégia, uma busca em descida na vizinhança é feita com movimento de troca de uma fornada por outra. Para cada gene buscamos uma outra 
liga que melhor se adapta à programação proposta pelo indivíduo. Essa operação requer $(T l * L) *(K-1)$ avaliações para encontrar qual das soluções é a de menor custo segundo a estratégia de máxima descida.

Como alternativa para diminuir o número de vizinhos a serem explorados e assim reduzir o número de avaliações, fizemos uma alteração na estratégia, buscamos qual das fornadas que, quando eliminada do plano de produção apresenta o plano de menor valor na função de avaliação. Esta operação requer $(T l * L)$ avaliações. A seguir, buscamos qual a liga que quando adicionada nesta lacuna apresenta o plano de menor valor na função de avaliação. Esta operação requer $(K-1)$ avaliações. Com esta estratégia, são necessárias $(T l * L)+(K-1)$ avaliações.

Duas aplicações foram estudadas para a busca local. Na primeira, aplicamos a busca local ao melhor indivíduo da população a cada geração. Se uma solução vizinha de menor valor for encontrada, torna-se a nova solução corrente e o algoritmo continua. Caso contrário, a solução corrente é um ótimo local em relação à vizinhança adotada. Se na geração seguinte o melhor indivíduo não evoluiu, sorteamos outro indivíduo dentre os 4 melhores indivíduos para a realização da busca local.

Na segunda aplicação, a busca local é utilizada juntamente com o mecanismo de seleção com tempo de maturação. Após gerar os descendentes e antes de reservá-los ao tempo de maturação, submetemo-os à busca local. Quando vizinhos de melhor solução são encontrados, determinamos um tempo de maturação, em geral, maior que o tempo determinado aos descendentes. Por fim, o mecanismo de seleção escolhe os melhores indivíduos entre a população, os descendentes maturados e os vizinhos maturados.

Testes computacionais indicaram que a aplicação da estratégia de busca local é um bom procedimento para acelerar a evolução da população no algoritmo genético.

\subsection{Path relinking}

A estratégia de path relinking consiste em a partir de uma solução origem, realizar trocas de genes para chegar a uma solução guia, neste caminho de uma solução a outra espera-se encontrar uma solução melhor que a solução guia.

Na solução origem, avaliamos a troca de um gene pelo valor do gene correspondente na solução guia, essa avaliação é feita para todos os genes possíveis. Na melhor solução encontrada, o valor do gene trocado é fixado. Na fase seguinte, são avaliadas soluções 
com uma segunda troca e o gene fixado; essa avaliação é feita para todas as combinações possíveis. Na melhor solução encontrada, fixamos o valor do gene trocado e repetimos a operação até que a solução origem seja idêntica à solução guia. Se alguma das soluções avaliadas durante o caminho for melhor que a solução do melhor indivíduo da população, atualizamos a melhor solução. Ilustramos na Figura 6 um exemplo da estratégia de path relinking aplicada à indivíduos de 4 genes, em que, (o) é a solução origem e (g) é a solução guia.

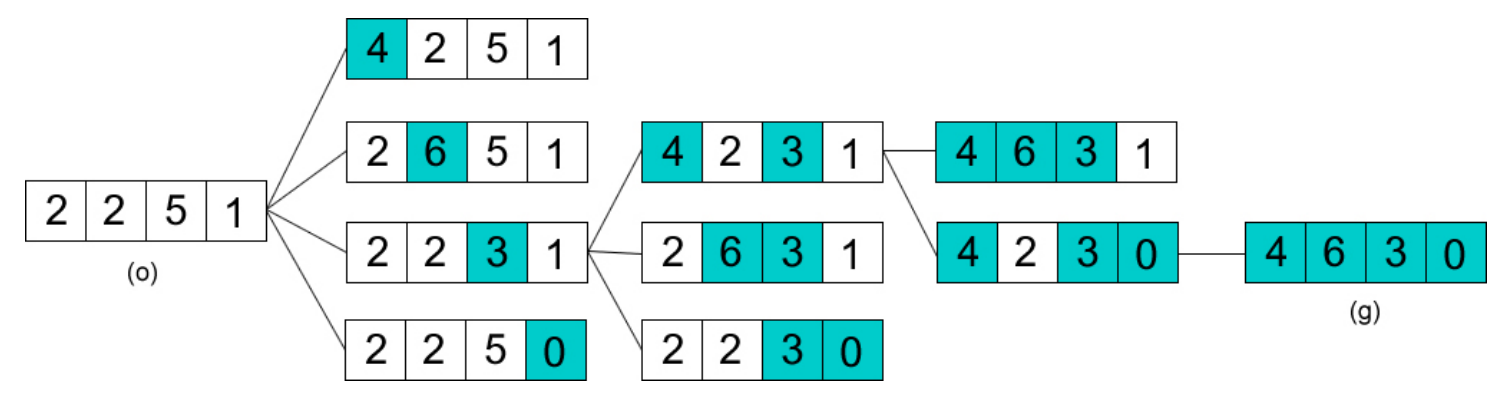

Figura 6: Esquema da estratégia de path relinking.

A operação é aplicada no algoritmo genético entre os cinco melhores indivíduos, assim, percorremos 4 caminhos: (origem: segundo melhor indivíduo; guia: melhor indivíduo), (origem: terceiro melhor indivíduo; guia: melhor indivíduo), (origem: quarto melhor indivíduo; guia: melhor indivíduo), (origem: quinto melhor indivíduo; guia: melhor indivíduo). Esta estratégia é aplicada na primeira e a cada 25 gerações, pois, testes computacionais com outras frequências de aplicação da estratégia mostraram ser a mais bem sucedida. 


\section{Testes computacionais para a abordagem de avaliação via heurística lagrangiana}

O método de solução proposto foi desenvolvido em linguagem $\mathrm{C}$ e compilado com Code::Blocks/GCC. As instâncias foram submetidas aos testes utilizando um microcomputador Pentium 4 - 2,8 GHz, com 1GB de memória RAM e sistema operacional Windows $\mathrm{XP}$.

O algoritmo genético, pelo caráter aleatório dos operadores, pode, a cada execução apresentar como soluções finais mínimos locais distintos, convergindo as vezes para o mínimo global. Nos testes computacionais, para que a aleatoriedade não prejudique a análise dos resultados, todos os experimentos foram executados em 10 ensaios. Destes ensaios extraímos a média, a melhor e a pior solução, o que nos permite avaliar quão robusto é o método.

Para definição dos parâmetros e operadores utilizados pelo algoritmo genético proposto no Capitulo 5 utilizamos como Instância Teste uma carteira de pedidos de uma fundição de pequeno porte situada na cidade de São Carlos. A carteira é composta por pedidos de 383 itens, de 19 diferentes tipos de ligas, demandando 29311 quilos de liga fundida para o vazamento dos itens. O horizonte de planejamento $(T)$ é de 5 dias, com capacidade máxima de produção do forno de 18000 quilos de liga fundida. São consideradas ainda, no máximo 10 cargas do forno por dia $(L)$ e capacidade do forno $($ Cap $)$ de $360 \mathrm{Kg}$. Este estudo de caso foi apresentado em (TONAKI, 2006).

\subsection{Cálculo dos custos de atraso e de antecipação}

Para comparação dos resultados entre os métodos, adotamos o cálculo dos custos de antecipação $\left(H_{i t}^{+}\right)$e atraso $\left(H_{i t}^{-}\right)$dos itens como reportado por Araujo (2003) e Tonaki 
(2006).

Conforme apresentado em (ARAUJO, 2003), $\alpha_{i, t}$ representa os dias de atraso de entrega do pedido do item $i$ no período $t$ (para pedidos que não estão em atraso, $\alpha_{i, t}$ tem valores não positivos, dependendo da quantidade de dias entre o início da programação e o dia de entrega do pedido e $\alpha_{i, t}=0$ significa que o prazo de entrega do item vence no dia em que está sendo feita a programação).

As demandas $d_{i, t}$ são consideradas positivas somente nos períodos múltiplos de $L$, ou seja, ao final de cada dia de programação. Portanto, os custos pelo atraso e antecipação também são positivos somente nos períodos múltiplos de $L$ e são calculados da seguinte forma: para $t \neq L, 2 L, 3 L, \ldots ; H_{i t}^{+}=H_{i t}^{-}=0$. Para $t=L, 2 L, 3 L, \ldots$ e considerando $G$ um número grande; se $\alpha_{i, t} \geq 0$ então $H_{i, t}^{-}=\rho_{i}\left(\alpha_{i, t}+1\right)$ e $H_{i, t}^{+}=G$, senão, $H_{i, t}^{+}=\rho_{i} / 10$ e $H_{i, t}^{-}=G$.

\subsection{Definição dos componentes do algoritmo genético}

Segundo (LARRANAGA; LOZANO, 2001), o desempenho dos algoritmos evolutivos depende da escolha de um conjunto de parâmetros, determinados depois de testes experimentais. Logo, a partir de testes preliminares aplicados à Instância Teste definimos os parâmetros e componentes que melhores se adaptam ao problema.

São comparadas três estratégias para a geração da população inicial, duas visões para o cruzamento, duas para a mutação, dois tipos de mecanismos de seleção e sua atuação combinada com uma estratégia de melhoria dos indivíduos através de busca local, aplicação de uma estratégia de melhoria por path relinking e, por fim, a influência do acréscimo do critério de parada adotado.

\subsubsection{Geração da população inicial}

Para a comparação entre os três tipos de geração de população inicial discutidas na Seção 5.2, foram gerados 10 indivíduos para cada população e os valores de avaliação foram comparados com a valor de solução da heurística lagrangiana $\left(H A_{S}\right)$ proposta por (TONAKI, 2006). A Figura 7 ilustra os resultados.

Podemos observar que dentre os testes, a geração pseudo-gulosa da população inicial é a que gerou indivíduos de melhor qualidade, ou seja, variando seu valor no intervalo de $[31 \% ; 112 \%]$ da solução de $H A_{S}$. Os indivíduos gerados aleatoriamente estão entre 


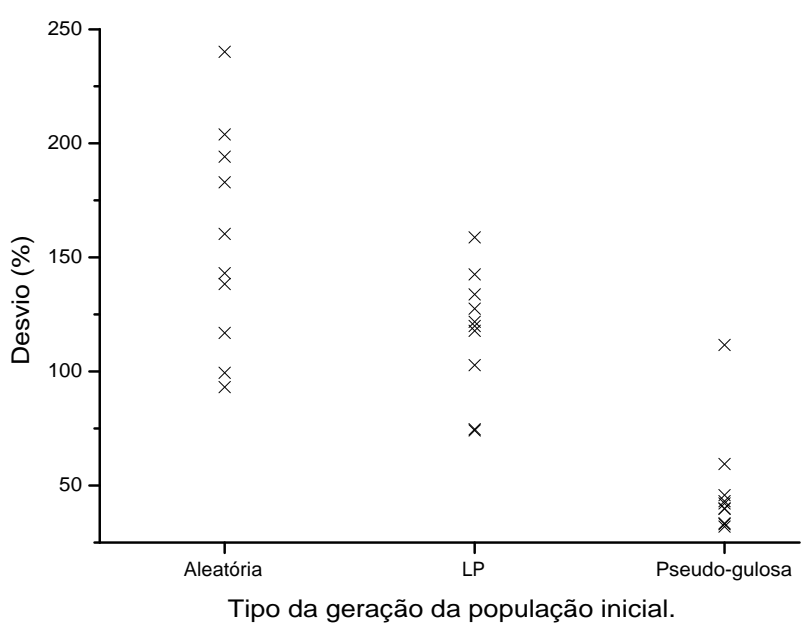

Figura 7: Geração da população inicial.

[93\%;241\%] da solução de $H A_{S}$ e os indivíduos gerados pela solução relaxada (LP) estão entre $[74 \% ; 159 \%]$ da solução de $H A_{S}$.

Dentre as três possibilidades de geração da população inicial testadas, escolhemos a pseudo-gulosa por gerar indivíduos de melhor qualidade.

\subsubsection{Cruzamento}

Dentre os dois cruzamentos propostos, a partir de testes preliminares, optamos pela utilização do cruzamento baseado no custo das ligas na solução, pois, além de auxiliar a evolução do algoritmo genético, reduz o tempo gasto na execução do componente de avaliação que é o procedimento mais custoso computacionalmente.

A avaliação do indivíduo é feita a partir da programação de cada liga para o período de planejamento, se um indivíduo transmite ao descendente as melhores programações das ligas, fica dispensável a avaliação para essas configurações, pois o cálculo para avaliações já realizadas é armazenado na estrutura de árvore.

\subsubsection{Taxa de mutação}

Larranaga e Lozano (2001) apontam que muitos pesquisadores utilizam valores pequenos para a taxa de mutação, tal como $1 / n$, em que, $n$ é o número de genes do cromossomo. Para a Instância Teste, a taxa de mutação seria de $2 \%$.

Testes computacionais foram realizados com a taxa de mutação aplicada a cada gene 
e o algoritmo genético composto com a geração da população inicial pseudo-gulosa, cruzamento baseado no custo das ligas na solução, seleção elitista dos indivíduos e critério de parada com limite de 200 gerações. Algumas variações na taxa de mutação foram testadas e os resultados são expostos na Tabela 2.

Tabela 2: Definição da taxa de mutação.

\begin{tabular}{c|ccc|c}
\hline $\begin{array}{c}\text { Taxa de } \\
\text { mutação }\end{array}$ & $\begin{array}{c}\text { Melhoria } \\
\text { mínima }\end{array}$ & $\begin{array}{c}\text { Melhoria } \\
\text { média }\end{array}$ & $\begin{array}{c}\text { Melhoria } \\
\text { máxima }\end{array}$ & $\begin{array}{c}\text { Tempo } \\
\text { médio (s) }\end{array}$ \\
\hline $0,50 \%$ & $3,59 \%$ & $1,26 \%$ & $-0,60 \%$ & 2047 \\
$0,75 \%$ & $3,72 \%$ & $0,56 \%$ & $-2,40 \%$ & 4906 \\
$1,00 \%$ & $2,37 \%$ & $-0,87 \%$ & $-3,84 \%$ & 5461 \\
$2,00 \%$ & $0,35 \%$ & $-1,30 \%$ & $-3,79 \%$ & 7791 \\
$3,00 \%$ & $1,84 \%$ & $-0,80 \%$ & $-3,85 \%$ & 10878 \\
\hline
\end{tabular}

A coluna Melhoria mínima indica a diferença percentual entre a pior solução encontrada pelo $A G_{H L}$ e a solução da heurística lagrangiana $\left(H A_{S}\right)$; a coluna Melhoria máxima indica a diferença percentual entre a melhor solução encontrada pelo algoritmo genético com avaliação via heurística lagrangiana $\left(A G_{H L}\right)$ e a solução da $H A_{S}$; a coluna Melhoria média indica a diferença percentual entre a média das soluções encontradas pelo $A G_{H L}$ e a solução da $H A_{S}$; e foram calculadas da forma:

$$
\text { Melhoria }=\frac{\left(A G_{H L}-H A_{S}\right)}{H A_{S}} * 100 .
$$

Dentre as diferentes taxas de mutação testadas, consideramos razoáveis as taxas de $1 \%$ e $2 \%$ pela melhoria que pode proporcionar ao método comparado com o tempo gasto na execução.

Outra proposta que testamos foi determinar uma taxa individual de mutação para cada indivíduo e a partir disso, alterar 1, 2 ou 3 genes. Essa taxa visa aplicar diversidade à população pela operação de mutação. A Figura 8 e a Tabela 3 mostram, utilizando diferentes taxas individuais de mutação, os resultados do algoritmo genético. As colunas da Tabela 3 são equivalentes às da Tabela 2.

Com a realização dos testes com taxa de mutação, os resultados mostram que para o problema estudado neste trabalho e com os parâmetros anteriormente determinados, a taxa individual de mutação de $50 \%$ garante uma boa evolução da população em tempo considerável aceitável quando comparado com taxas individuais de mutação que produzem resultados igualmente bons. 
Tabela 3: Definição da taxa individual de mutação.

\begin{tabular}{c|ccc|c}
\hline $\begin{array}{c}\text { Taxa de } \\
\text { mutação }\end{array}$ & $\begin{array}{c}\text { Melhoria } \\
\text { mínima }\end{array}$ & $\begin{array}{c}\text { Melhoria } \\
\text { média }\end{array}$ & $\begin{array}{c}\text { Melhoria } \\
\text { máxima }\end{array}$ & $\begin{array}{c}\text { Tempo } \\
\text { médio (s) }\end{array}$ \\
\hline $10 \%$ & $9,30 \%$ & $4,92 \%$ & $-0,79 \%$ & 2578 \\
$20 \%$ & $0,85 \%$ & $-0,62 \%$ & $-3,03 \%$ & 3142 \\
$30 \%$ & $-0,25 \%$ & $-2,26 \%$ & $-3,66 \%$ & 3671 \\
$40 \%$ & $-0,59 \%$ & $-2,53 \%$ & $-4,66 \%$ & 4149 \\
$50 \%$ & $-1,61 \%$ & $-3,01 \%$ & $-4,31 \%$ & 4633 \\
$60 \%$ & $-0,83 \%$ & $-3,02 \%$ & $-4,15 \%$ & 4794 \\
$70 \%$ & $-1,17 \%$ & $-3,50 \%$ & $-4,94 \%$ & 5113 \\
$80 \%$ & $-2,40 \%$ & $-3,89 \%$ & $-5,56 \%$ & 5879 \\
$90 \%$ & $-2,42 \%$ & $-3,73 \%$ & $-4,92 \%$ & 5997 \\
$100 \%$ & $-0,24 \%$ & $-3,16 \%$ & $-4,51 \%$ & 6727 \\
\hline
\end{tabular}
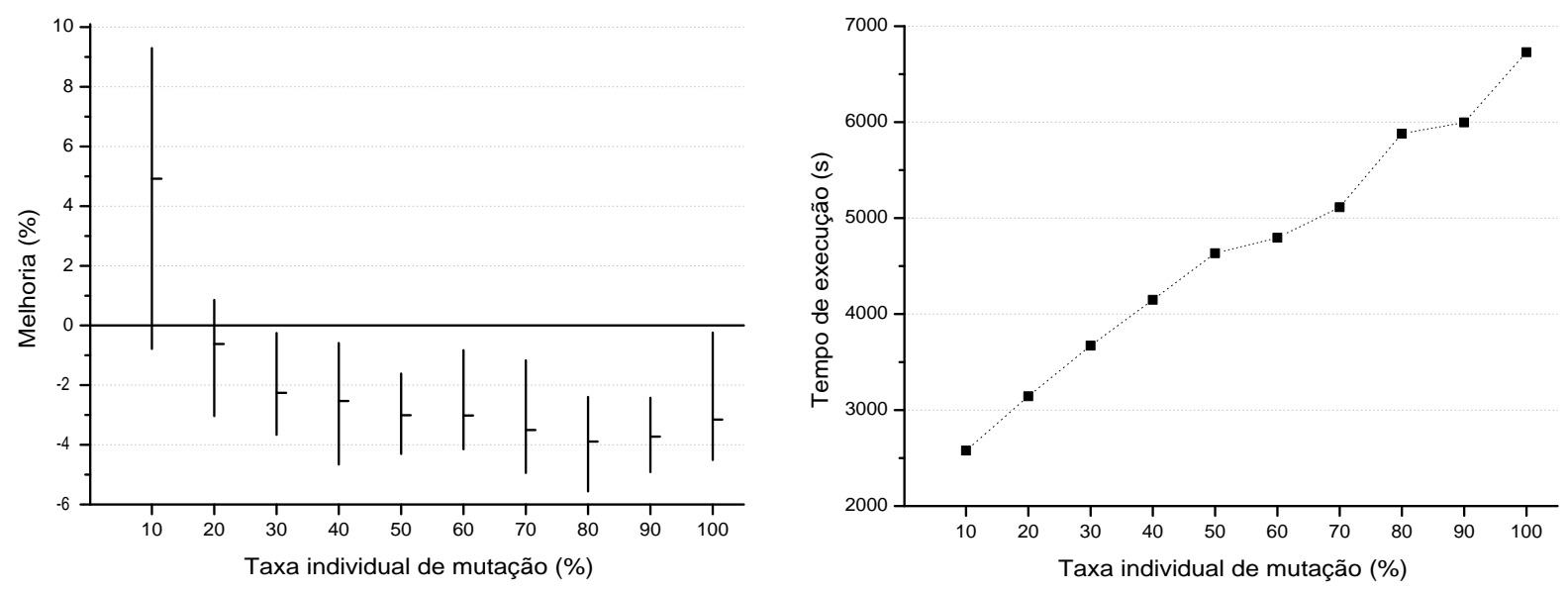

Figura 8: Definição da taxa individual de mutação.

\subsubsection{Mecanismo de seleção}

Um mecanismo de seleção com tempo de maturação foi proposto com propósito de evitar que a população tenha uma convergência prematura. Testes para a seleção com tempo de maturação foram realizados com os componentes do algoritmo genético $\left(A G_{H L}\right.$ mat) fixados como discutido anteriormente (10 indivíduos na população, geração da população inicial pseudo-gulosa, cruzamento baseado no custo das ligas na solução, taxa individual de mutação de $50 \%$ e critério de parada com limite de 200 gerações). A Tabela 4 mostra os resultados de melhoria e o tempo de execução gasto e comparados com o mesmo algoritmo genético com seleção elitista $\left(A G_{H L}\right)$.

Tabela 4: Resultados para os mecanismos de seleção propostos.

\begin{tabular}{c|ccc|c}
\hline & $\begin{array}{c}\text { Melhoria } \\
\text { mínima }\end{array}$ & $\begin{array}{c}\text { Melhoria } \\
\text { média }\end{array}$ & $\begin{array}{c}\text { Melhoria } \\
\text { máxima }\end{array}$ & $\begin{array}{c}\text { Tempo } \\
\text { médio (s) }\end{array}$ \\
\hline$A G_{H L}$ & $-1,61 \%$ & $-3,01 \%$ & $-4,31 \%$ & 4633 \\
$A G_{H L}$ mat & $3,65 \%$ & $0,55 \%$ & $-1,48 \%$ & 7727 \\
\hline
\end{tabular}


A partir dos resultados da Tabela 4, podemos observar que o estágio de maturação, por si só, não colabora na evolução da população, no entanto, optamos por testá-lo combinado com a estratégia de busca local.

\subsubsection{Busca local}

Esperamos encontrar indivíduos melhores adaptados com a aplicação de uma busca local (BL) ao melhor indivíduo da população. Para tanto, realizamos testes com os dois mecanismos de seleção propostos.

Tabela 5: Resultados para a aplicação de busca local.

\begin{tabular}{c|ccc|c}
\hline & $\begin{array}{c}\text { Melhoria } \\
\text { mínima }\end{array}$ & $\begin{array}{c}\text { Melhoria } \\
\text { média }\end{array}$ & $\begin{array}{c}\text { Melhoria } \\
\text { máxima }\end{array}$ & $\begin{array}{c}\text { Tempo } \\
\text { médio (s) }\end{array}$ \\
\hline$A G_{H L}$ & $-1,61 \%$ & $-3,01 \%$ & $-4,31 \%$ & 4633 \\
$A G_{H L}$ mat $+B L$ & $-1,88 \%$ & $-3,76 \%$ & $-5,46 \%$ & 13753 \\
$A G_{H L}+B L$ & $-2,03 \%$ & $-3,46 \%$ & $-4,86 \%$ & 7314 \\
\hline
\end{tabular}

Podemos observar na Tabela 5 que a estratégia de busca local é um bom procedimento para encontrar soluções de melhor qualidade. No procedimento $A G_{H L}$ mat $+B L$, o método comportou-se como esperado, a estratégia de busca local fornecendo bons indivíduos e o mecanismo de seleção com tempo de maturação evitando mínimos locais. Apesar dos resultados com a estratégia de busca local serem em média um pouco melhores que o algoritmo genético sem busca local e/ou maturação, o tempo de execução gasto é bem superior, o que era esperado, pois requer um número maior de avaliações.

A partir dos testes realizados até o momento, definimos o procedimento $A G_{H L}$ como melhor tempo-benefício entre todos os comparados. Os componentes extras testados até o momento não colaboraram para melhorar o tempo computacional do algoritmo e tampouco melhoram significativamente a qualidade das soluções.

\subsubsection{Path relinking}

Os testes realizados na Instância Teste utilizando a estratégia de busca local mostraram resultados promissores, porém, com grande custo computacional. Outra estratégia estudada foi a utilização do procedimento de path relinking. Testes computacionais foram realizados aplicando path relinking em toda geração $\left(A G_{H L} P R 1\right)$, na primeira e a cada 25 gerações $\left(A G_{H L} P R 25\right)$, na primeira e a cada 50 gerações $\left(A G_{H L} P R 50\right)$ e na primeira e a cada 100 gerações $\left(A G_{H L} P R 100\right)$. A Tabela 6 resume os resultados dos testes comparados com o resultado do algoritmo sem aplicação da melhoria $\left(A G_{H L}\right)$. 
Tabela 6: Resultados para a estratégia de path relinking.

\begin{tabular}{c|ccc|c}
\hline & $\begin{array}{c}\text { Melhoria } \\
\text { mínima }\end{array}$ & $\begin{array}{c}\text { Melhoria } \\
\text { média }\end{array}$ & $\begin{array}{c}\text { Melhoria } \\
\text { máxima }\end{array}$ & $\begin{array}{c}\text { Tempo } \\
\text { médio (s) }\end{array}$ \\
\hline$A G_{H L}$ & $-1,61 \%$ & $-3,01 \%$ & $-4,31 \%$ & 4633 \\
$A G_{H L} P R 1$ & $-2,67 \%$ & $-4,56 \%$ & $-5,96 \%$ & 6834 \\
$A G_{H L} P R 25$ & $-2,74 \%$ & $-4,27 \%$ & $-6,61 \%$ & 5646 \\
$A G_{H L} P R 50$ & $-2,80 \%$ & $-3,72 \%$ & $-5,21 \%$ & 5393 \\
$A G_{H L} P R 100$ & $-0,25 \%$ & $-3,30 \%$ & $-4,52 \%$ & 6089 \\
\hline
\end{tabular}
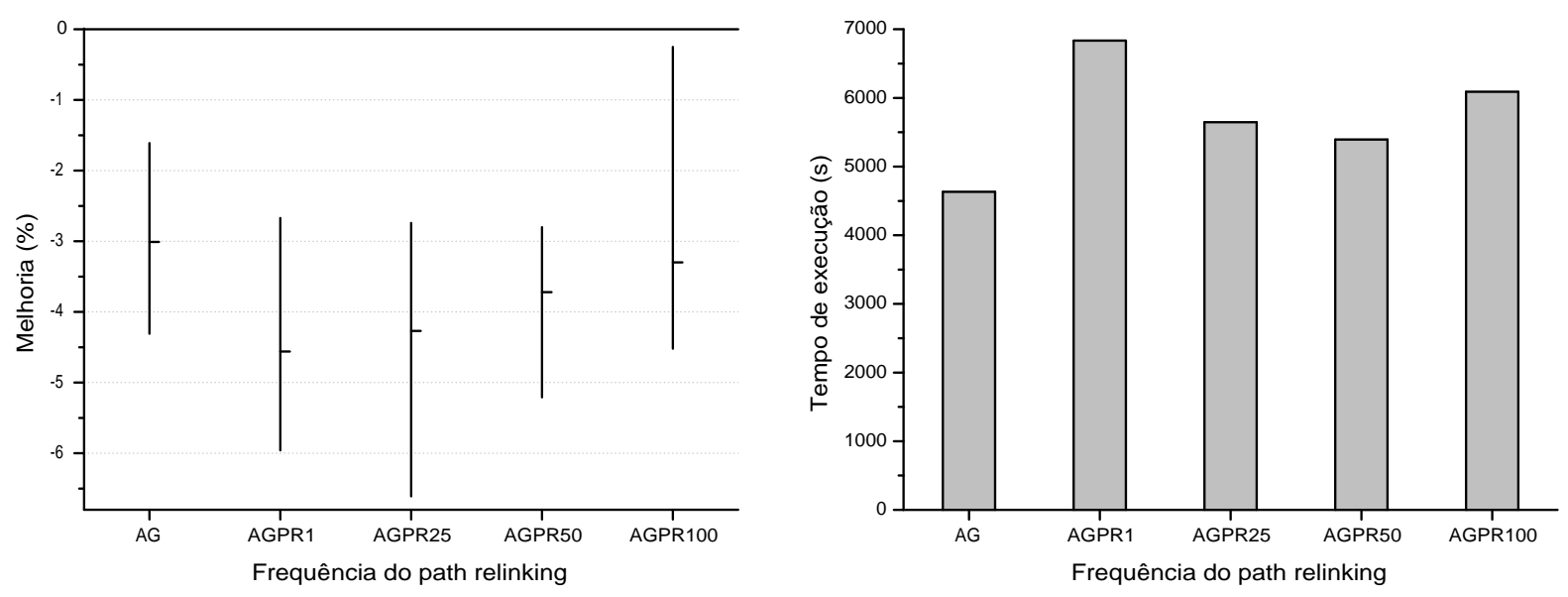

Figura 9: Resultados para a estratégia de path relinking.

Como podemos ver na Figura 9, o procedimento $A G_{H L} P R 1$ apresenta melhor solução em média, porém, com custo computacional maior que os outros procedimentos. O procedimento $A G_{H L} P R 25$ apresenta, em média, solução parecida que o $A G_{H L} P R 1$, porém, com custo computacional aceitável e, quando comparado com o algoritmo sem path relinking, observamos que a solução média tem melhoria de $1 \%$ e no melhor caso a melhoria pode chegar a $2 \%$.

Adotamos a estratégia de path relinking aplicado à primeira geração e a cada 25 gerações ao algoritmo genético com geração da população inicial pseudo-gulosa, cruzamento baseado no custo das ligas na solução, taxa individual de mutação de $50 \%$, seleção elitista dos indivíduos e critério de parada com limite de 200 gerações.

\subsubsection{Critério de parada}

Inicialmente, os testes realizados tiveram como critério de parada 200 gerações, porém, outros testes foram realizados tendo como critério de parada 400, 600, 800 e 1000 gerações. A contribuição na minimização no valor da função objetivo devido ao aumento do número máximo de gerações se mostrou pouco significativa quando comparada ao tempo de pro- 
cessamento das gerações adicionais. Para os testes com o critério de parada com 400 iterações, obtivemos melhoria de 0,95\% em média, adicionais à melhoria obtida com o critério de parada de 200 iterações. Para os testes com o critério de parada com 600 iterações, obtivemos melhoria de 0,28\% em média, adicionais à melhoria obtida com o critério de parada de 400 iterações. Para os testes com o critério de parada com 800 iterações, obtivemos melhoria de 0,09\% em média, adicionais à melhoria obtida com o critério de parada de 600 iterações. Para os testes com o critério de parada com 1000 iterações, obtivemos melhoria de 0,0041\% em média, adicionais à melhoria obtida com o critério de parada de 800 iterações. A Figura 10 mostra o comportamento da evolução média do algoritmo genético proposto. Logo, mantivemos como critério de parada 200 gerações.

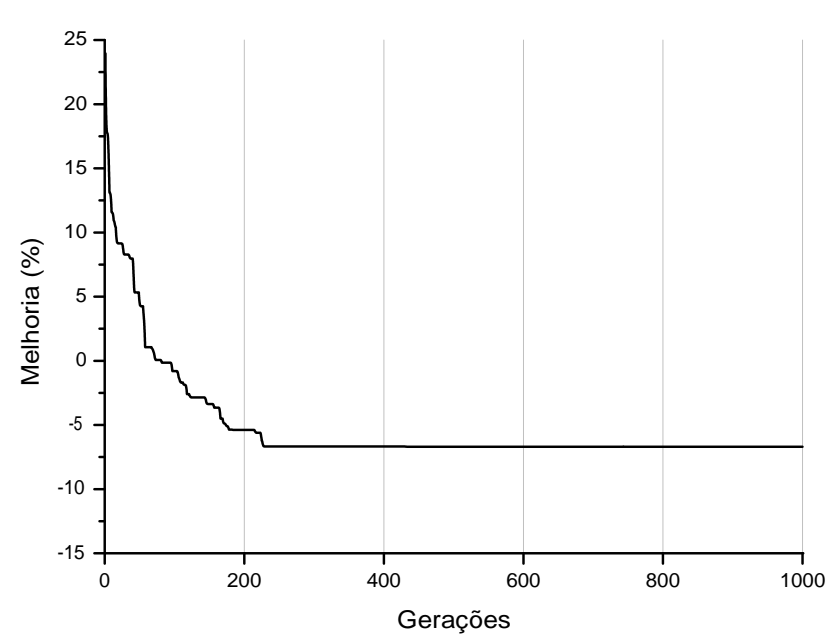

Figura 10: Comportamento da evolução do algoritmo genético.

\subsection{Problemas sem penalidade para subutilização do forno}

Assim, como a carteira de pedidos obtida junto à fundição objeto do estudo em (TONAKI, 2006) e deste trabalho, geralmente, tem-se carteiras de pedidos muito atrasadas e a demanda dos itens excede a capacidade do forno disponível para um horizonte de planejamento de 5 dias. Em vista disso, outras instâncias foram criadas por Tonaki (2006) a partir da carteira de pedidos completa que contêm carteiras com 80\%, 90\% e $100 \%$ dos itens atrasados, carteiras com as ligas mais frequentes e a carteira completa, variando o horizonte de planejamento de 3 e 5 dias. Os detalhes das carteiras criadas são 
expostos na Tabela 7.

Tabela 7: Detalhes das instâncias utilizadas nos testes computacionais.

\begin{tabular}{c|ccccc}
\hline Instância & Ligas & Itens & $\begin{array}{c}\text { Horizonte de } \\
\text { Planejamento (dias) }\end{array}$ & $\begin{array}{c}\text { Capacidade } \\
\text { máxima }(\mathrm{kg})\end{array}$ & Demanda $(\mathrm{kg})$ \\
\hline 1 & 5 & 165 & 3 & 10800 & 13863,90 \\
2 & 5 & 165 & 5 & 18000 & 13863,90 \\
3 & 5 & 228 & 3 & 10800 & 20139,45 \\
4 & 5 & 293 & 5 & 18000 & 24040,45 \\
5 & 16 & 225 & 3 & 10800 & 17211,30 \\
6 & 16 & 225 & 5 & 18000 & 17211,30 \\
7 & 16 & 224 & 3 & 10800 & 15441,50 \\
8 & 16 & 224 & 5 & 18000 & 15441,50 \\
9 & 15 & 224 & 3 & 10800 & 13731,30 \\
10 & 15 & 224 & 5 & 18000 & 13731,30 \\
11 & 19 & 383 & 5 & 18000 & 29311,95 \\
\hline
\end{tabular}

As Instâncias 1 e 2 consideram somente os itens atrasados das 5 ligas mais frequentes. As Instâncias 3 e 4 consideram todos os itens das 5 ligas mais frequentes. As Instâncias 5 e 6 consideram $100 \%$ dos itens atrasados das 19 ligas da carteira de pedidos completa. As Instâncias 7 e 8 consideram aproximadamente 90\% dos itens atrasados da carteira completa. As Instâncias 9 e 10 consideram aproximadamente $80 \%$ dos itens atrasados da carteira completa. A Instância 11 é composta pelos itens e ligas da carteira completa de pedidos.

Os resultados computacionais para o algoritmo genético proposto aplicado às 11 instâncias são comparados com os resultados obtidos pela heurística lagrangiana proposta por (TONAKI, 2006) e são apresentados na Tabela 8.

Tabela 8: Resultados do algoritmo genético com heurística lagrangiana.

\begin{tabular}{c|cc|c|cc}
\hline Instância & $H A_{S}$ & $A G_{H L}$ & Melhoria (\%) & Tempo $H A_{S}(\mathrm{~s})$ & Tempo $A G_{H L}(\mathrm{~s})$ \\
\hline 1 & 196747,61 & 173411,50 & $\mathbf{- 1 1 , 8 6}$ & 4,44 & 229 \\
2 & 200079,36 & 176960,20 & $\mathbf{- 1 1 , 5 5}$ & 25,88 & 2923 \\
3 & 224868,08 & 201160,90 & $\mathbf{- 1 0 , 5 4}$ & 6,11 & 342 \\
4 & 260531,56 & 241338,60 & $\mathbf{- 7 , 3 7}$ & 45,72 & 6213 \\
5 & 370888,69 & 341633,70 & $\mathbf{- 7 , 8 9}$ & 6,06 & 257 \\
6 & 423009,09 & 407545,20 & $\mathbf{- 3 , 6 6}$ & 35,24 & 3198 \\
7 & 337705,34 & 303213,60 & $\mathbf{- 1 0 , 2 1}$ & 6,51 & 260 \\
8 & 343584,88 & 337654,00 & $\mathbf{- 1 , 7 3}$ & 35,16 & 3013 \\
9 & 297808,69 & 270312,90 & $\mathbf{- 9 , 2 3}$ & 5,92 & 252 \\
10 & 318432,47 & 282248,10 & $\mathbf{- 1 1 , 3 6}$ & 35,38 & 2980 \\
11 & 541116,38 & 517074,10 & $\mathbf{- 4 , 4 4}$ & 59,92 & 6949 \\
\hline Média & & & $-8,16 \%$ & 24,21 & 2420 \\
\hline
\end{tabular}

Na Tabela 8, a coluna $H A_{S}$ indica o valor da função objetivo para a heurística lagrangiana, a coluna $A G_{H L}$ indica o valor médio da função objetivo para o algoritmo genético, a coluna Melhoria indica a melhoria média obtida pelo método proposto em relação ao 
resultado da heurística lagrangiana e é calculada de forma equivalente à apresentada na Tabela 2. Os tempos de execução dos métodos são apresentados em segundos nas colunas Tempo $H A_{S}$ e Tempo $A G_{H L}$.

O algoritmo genético apresenta resultados melhores que a heurística lagrangiana, com $8,1 \%$ de melhoria em média, porém o tempo computacional é muito superior.

A Tabela 9 apresenta os resultados de avaliação da utilização do forno para o algoritmo genético proposto aplicado às 11 instâncias comparadas com os resultados obtidos pelo $H A_{S}$.

Tabela 9: Utilização do forno pelo algoritmo genético.

\begin{tabular}{c|cc}
\hline Instância & $S u b_{H A_{S}}(\mathrm{~kg})$ & $S u b_{A G_{H L}}(\mathrm{~kg})$ \\
\hline 1 & 1131,30 & $\mathbf{1 1 1 , \mathbf { 1 4 }}$ \\
2 & 4214,50 & $\mathbf{1 6 1 6 , \mathbf { 1 0 }}$ \\
3 & $\mathbf{1 5 , 2 0}$ & 39,81 \\
4 & $\mathbf{1 5 5 , 2 5}$ & 171,88 \\
5 & 867,15 & $\mathbf{8 0 6 , 9 9}$ \\
6 & 1987,00 & $\mathbf{1 9 0 6 , 5 3}$ \\
7 & 1221,00 & $\mathbf{8 0 4 , 2 9}$ \\
8 & 2768,60 & $\mathbf{2 2 8 0 , 8 6}$ \\
9 & 867,15 & $\mathbf{7 6 8 , 4 7}$ \\
10 & 4415,00 & $\mathbf{2 9 0 2 , 9 4}$ \\
11 & 1484,70 & $\mathbf{1 3 5 7 , 2 3}$ \\
\hline Média & 1738,80 & $\mathbf{1 1 6 0 , 5 7}$ \\
\hline
\end{tabular}

Na Tabela 9, a coluna $S u b_{H A_{S}}$ indica a subutilização do forno em quilos de liga fundida dada pelo planejamento da produção da heurística lagrangiana e a coluna $S u b_{A G_{H L}}$ indica a subutilização do forno em quilos de liga fundida dada pelo planejamento da produção do algoritmo genético.

Podemos observar que o planejamento da produção obtido pelo algoritmo genético desperdiça, em média, menos liga fundida que o planejamento obtido pelo método da heurística lagrangiana.

\subsection{Problemas com penalidade para subutilização do forno}

Tonaki (2006) propôs penalizar a subutilização do forno e obteve resultados que diminuíram o desperdício de capacidade.

Para o algoritmo genético proposto, a penalidade é somada na função de avaliação da 
população e é calculada da seguinte forma:

$$
\text { penalidade }=\sigma \sum_{t=1}\left(\text { Cap }-\sum_{i=1}\left(\rho_{i} X_{i, t}\right)\right)
$$

em que:

- $\sigma$ : o valor da penalidade para cada quilo de capacidade do forno subutilizado;

- Cap: capacidade do forno;

- $\rho_{i}$ : peso bruto em quilos do item $i$ e;

- $X_{i, t}$ : quantidade produzida do item $i$ no subperíodo $t$.

Na Tabela 10 apresentamos os resultados de melhoria do valor de solução da Instância Teste aplicada ao algoritmo genético com penalidade $\left(A G_{H L}^{P}\right)$ quando comparados com o resultado da heurística lagrangiana com penalidade $\left(H A_{C}\right)$. Foram aplicadas penalidades de $25,50,75,100$ e 125 por quilo de subutilização do forno.

Tabela 10: Melhoria aplicando a penalidade à subutilização do forno.

\begin{tabular}{c|ccc}
\hline $\begin{array}{c}\text { Penalidade } \\
(\sigma)\end{array}$ & $\begin{array}{c}\text { Melhoria } \\
\text { mínima }\end{array}$ & $\begin{array}{c}\text { Melhoria } \\
\text { média }\end{array}$ & $\begin{array}{c}\text { Melhoria } \\
\text { máxima }\end{array}$ \\
\hline 0 & $-11,39 \%$ & $-12,78 \%$ & $-14,91 \%$ \\
25 & $-4,93 \%$ & $-6,92 \%$ & $-8,53 \%$ \\
50 & $-0,73 \%$ & $-4,44 \%$ & $-6,25 \%$ \\
75 & $1,63 \%$ & $-0,62 \%$ & $-3,52 \%$ \\
100 & $4,27 \%$ & $1,15 \%$ & $-3,88 \%$ \\
125 & $8,76 \%$ & $4,95 \%$ & $2,28 \%$ \\
\hline
\end{tabular}

Na Tabela 10, a coluna Melhoria mínima indica a diferença percentual entre o valor da pior solução encontrada pelo $A G_{H L}^{P}$ e o valor da solução da heurística lagrangiana com penalidade $\left(H A_{C}\right)$; a coluna Melhoria máxima indica a diferença percentual entre o valor da melhor solução encontrada pelo $A G_{H L}^{P}$ e o valor da solução da $H A_{C}$; a coluna Melhoria média indica a diferença percentual entre o valor da média das soluções encontradas pelo $A G_{H L}^{P}$ e o valor da solução da $H A_{C}$; e foram calculadas da forma:

$$
\text { Melhoria }=\frac{\left(A G_{H L}^{P}-H A_{C}\right)}{H A_{C}} * 100 .
$$

A Tabela 11 apresenta os resultados de avaliação da utilização do forno para o algoritmo genético com penalidade $\left(A G_{H L}^{P}\right)$ aplicado à Instância Teste.

Para a Instância Teste, a heurística lagrangiana com penalidade encontra um planejamento de produção com subutilização do forno de 134,60 quilos. Podemos notar na Figura 
Tabela 11: Subutilização do forno aplicando a penalidade.

\begin{tabular}{c|ccc}
\hline $\begin{array}{c}\text { Penalidade } \\
(\sigma)\end{array}$ & $\begin{array}{c}\text { Subutilização } \\
\text { mínima }(\mathrm{kg})\end{array}$ & $\begin{array}{c}\text { Subutilização } \\
\text { média }(\mathrm{kg})\end{array}$ & $\begin{array}{c}\text { Subutilização } \\
\text { máxima }(\mathrm{kg})\end{array}$ \\
\hline 0 & 1203,40 & 1357,23 & 1571,30 \\
25 & 663,20 & 753,64 & 876,65 \\
50 & 396,65 & 561,26 & 723,85 \\
75 & 326,80 & 405,20 & 601,30 \\
100 & 208,75 & 347,92 & 432,95 \\
125 & 147,30 & 196,15 & 211,55 \\
\hline
\end{tabular}

12 que com o algoritmo genético penalizando a subutilização, é possível obter redução no desperdício, porém, com piora no valor da função objetivo.
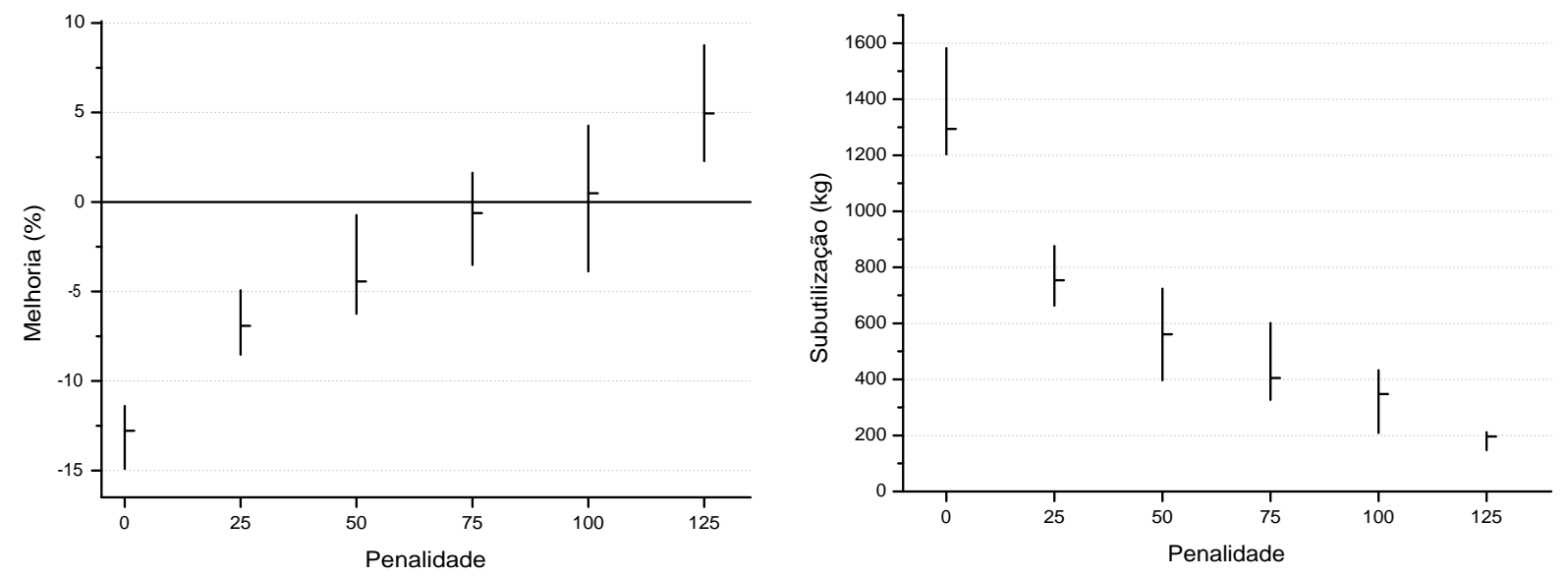

Tabela 12: Penalidade para subutilização do forno.

Utilizando a penalidade para subutilização do forno igual a 125, reduzimos o desperdício de 1357, 23 quilos para 196, 15 quilos (em média), porém, o valor da função objetivo é 4, 95\% pior que o valor encontrado pela heurística lagrangiana. Por outro lado, temos uma subutilização de 516, 26 quilos mantendo uma melhoria de 4,44\% se aplicarmos a penalidade igual a 50. Concluímos portanto que, caso seja mais significativo reduzir as perdas ao mínimo possível, a heurística lagrangiana é mais adequada, no entanto, se o custo total também for importante, o $A G_{H L}^{P}$ gera uma boa redução de compromisso com penalidade igual a 50 . 


\section{Abordagem pelo problema de corte unidimensional}

Quando observamos o problema estudado, notamos que a definição das peças pode ser abordada de maneira análoga ao problema de corte unidimensional, uma fornada com a liga fundida pode ser vista como uma barra e as peças utilizam um pedaço desta barra correspondente ao peso necessário da liga fundida para moldá-la. Por exemplo, uma fornada com produção de $120 \mathrm{Kg}$ de liga pode ser representada por um objeto de tamanho 120, outra fornada com produção de $360 \mathrm{Kg}$ pode ser representada por um objeto de tamanho 360, assim, temos objetos de tamanhos variados. Podemos "cortar" uma fornada em várias partes de forma que cada corte tem o "tamanho" necessário para a produção de um item. Na Figura 11 ilustramos um exemplo em que temos uma fornada de $360 \mathrm{Kg}$ (c), peças de diferentes pesos a serem produzidas com este tipo de liga (a), ou seja, os itens de tamanhos variados que podem ser cortados em um padrão de corte (b) do objeto maior que é a fornada.

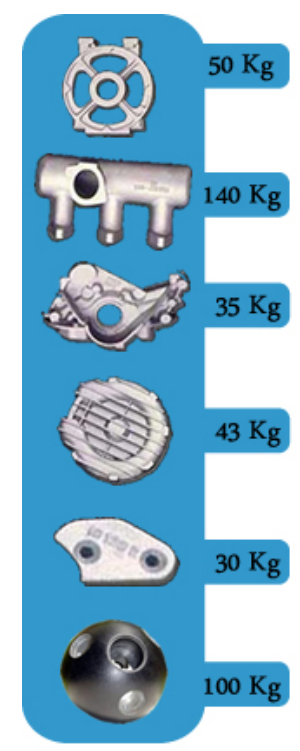

(a)

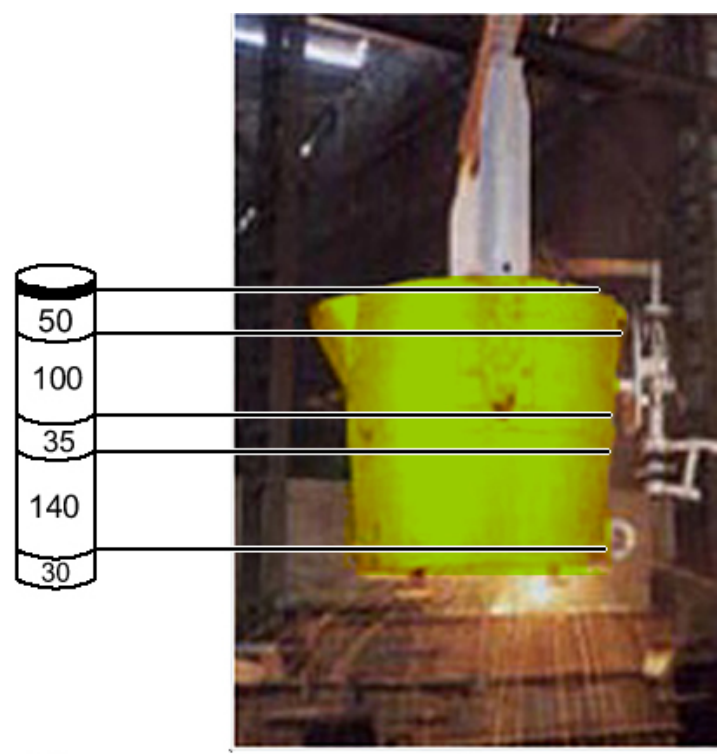

(c)

Figura 11: Problema de corte unidimensional em uma fornada. 
O problema de corte unidimensional visa determinar a forma que os objetos são cortados (padrão de corte) e quantas vezes esse padrão de corte será utilizado para atender a demanda.

No problema estudado, além de permitir a antecipação na produção dos itens, o atraso na produção é permitido, ou seja, a demanda de um item em um dado período pode ser atendida pela produção em períodos futuros. A disponibilidade dos objetos é restrita aos subperíodos em que há produção da liga, assim como somente os itens feitos desta liga podem ser produzidos sem exceder a demanda. Logo, dado um objeto $k$, de tamanho Cap, devemos determinar qual o padrão de corte $\mathbf{x}$, composto pelos itens de $S(k)$, que respeita a demanda e maximiza a função de utilidade dos itens $\left(g_{k}(\mathbf{x})\right)$. Este problema pode ser modelado como o problema da mochila restrita e, como temos vários subperíodos de planejamento, é necessário resolver um problema da mochila restrita para cada subperíodo a fim de determinar quais itens são produzidos pela liga fundida neste subperíodo.

Nessa abordagem utilizamos um método de enumeração implícita para o problema da mochila restrita para determinar o corte das peças. A seguir, o método é detalhado.

\subsection{Método de enumeração implícita para o problema da mochila restrita}

Considere o problema da mochila restrita:

Maximizar

$$
g_{k}(\mathbf{x})=\sum_{i=1}^{m} v_{i} x_{i}
$$

Sujeito à:

$$
\begin{aligned}
& \sum_{i=1}^{m} \rho_{i} x_{i} \leq \text { Cap } \\
& 0 \leq x_{i} \leq d_{i}, \text { inteiro } \quad i=1, \ldots, m ;
\end{aligned}
$$

em que:

- $m$ : número de itens que utilizam a liga $k$ (cada item utiliza um, e somente um tipo de liga);

- $v_{i}$ : valor de utilidade do item;

- $x_{i}$ : quantidade a ser produzida do item $i$; 
- $\rho_{i}$ : peso bruto $(\mathrm{kg})$ do item $i$;

- Cap: capacidade do forno $(\mathrm{kg})$;

- $d_{i}$ : demanda do item $i$

O valor de utilidade para o item $\left(v_{i}\right)$ é definido de forma que os itens mais atrasados tenham maior valor que os itens não atrasados, que também tenham possibilidade de serem produzidos antecipadamente. Na definição dos dias de atraso de um item $i\left(\alpha_{i}\right), \alpha_{i}$ recebe valor positivo referente aos dias de atraso, valor negativo para os dias que ainda faltam para entregar o pedido e $\alpha_{i}=0$ para quando o período em questão é o dia de entrega do pedido. Assim, definimos o valor de utilidade do item refletindo quão atrasado está a sua entrega.

Seja $T$ o número de dias do horizonte de planejamento e $t$ o dia em que $g_{k}(\mathbf{x})$ é determinado. Se $\alpha_{i}>0$, então $v_{i}=T+\rho_{i}\left(\alpha_{i}+t+1\right)$; senão, $v_{i}=T+\alpha_{i}-t$. Outros valores para a função utilidade foram testados, porém este é o que melhor expressa a necessidade da produção dos itens atrasados e a possibilidade de produção dos itens não atrasados.

Este problema pode ser resolvido por meio do algoritmo dado em (MARQUES, 2004) e é apresentado a seguir.

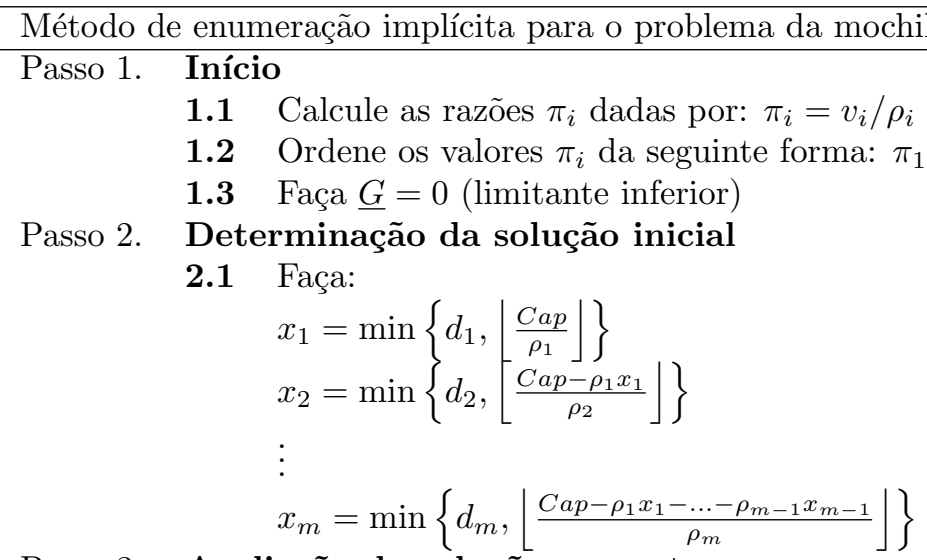

Passo 3. Avaliação da solução corrente e armazenamento da mais valiosa

3.1 Faça $g=v_{1} x_{1}+v_{2} x_{2}+\ldots+v_{m} x_{m}$

3.2 Se $\underline{G}<g$ faça:

3.2.1 $\underline{G}=g$ e $\mathrm{x}^{*}=\mathrm{x}$

Passo 4. Teste de parada e cálculo do limitante superior

4.1 Em $x$ determine o maior índice $r$ tal que $x_{r} \neq 0$

4.2 Se $x=(0, \ldots, 0)$ então Pare, $x^{*}$ é a solução ótima, senão:

4.3 (Cálculo do limitante superior)

Faça $\overline{C a}=C a p-\rho_{1} x_{1}-\rho_{2} x_{2}-\ldots-\rho_{r}\left(x_{r}-1\right) \mathrm{e}$

$\bar{G}=v_{1} x_{1}+v_{2} x_{2}+\ldots+v_{r}\left(x_{r}-1\right)$

4.3.1 Seja $h=r+1$

4.3.2 Faça $x_{m+1}=0, \rho_{m+1}=1$ e $d_{m+1}=0$ (variável de folga)

4.3.3 Enquanto $\left(\rho_{h} d_{h} \leq \overline{C a p}\right.$ e $\left.h \leq m\right)$ faça:

$\overline{C a p}=\overline{C a}-\rho_{h} \bar{d}_{h}$ e $\bar{G}=\bar{G}+v_{h} d_{h}$

$h=h+1$ 
Passo 5. Backtracking

4.3.4 Faça: $\bar{G}=\bar{G}+\frac{C^{\bar{a} p}}{\rho_{h}} v_{h}$

5.1 Se $\bar{G} \leq g$ faça $x_{r}=0$ e volte ao passo 4

5.2 Senão $(\bar{G}>g)$ faça

$x_{r}=x_{r}-1$

$x_{j}=\min \left\{d_{i},\left\lfloor\frac{C a p-\sum_{i=1}^{j-1} \rho_{i} x_{i}}{\rho_{j}}\right\rfloor\right\}, j=r+1, \ldots, m$ e volte ao Passo 3.

\subsection{Outros componentes para o algoritmo genético}

Os componentes e parâmetros utilizados no algoritmo genético com avaliação via problema da mochila restrita foram definidos da mesma forma que para o método proposto com avaliação via heurística lagrangiana:

- geração da população inicial pseudo-gulosa,

- critério de parada de 200 gerações,

- cruzamento baseado no planejamento da produção de cada liga,

- mutação com taxa individual de 50\%,

- mecanismo de seleção elitista e,

- estratégia de melhoria de indivíduos por path relinking na primeira e cada 25 gerações. 


\section{Testes computacionais para a abordagem de avaliação via problema da mochila}

O algoritmo genético proposto com avaliação via problema da mochila foi desenvolvido em linguagem C e compilado com Microsoft Visual C++ 2008 Express Edition. As instâncias foram submetidas aos testes utilizando um microcomputador Pentium $4-2,8 \mathrm{GHz}$, com 1GB de memória RAM e sistema operacional Windows XP.

As instância testadas são as descritas na Seção 6.3 e os componentes e parâmetros para o algoritmo genético são os mesmos do algoritmo genético que utiliza a heurística lagrangiana para a avaliação dos indivíduos.

\subsection{Problemas sem penalidade para subutilização do forno}

Os resultados computacionais para o algoritmo genético proposto, aplicado às 11 instâncias, são comparados com os resultados obtidos pelo método da heurística lagrangiana proposto por (TONAKI, 2006) e são apresentados na Tabela 13.

Tabela 13: Resultados do algoritmo genético com avaliação via problema da mochila.

\begin{tabular}{c|cc|c|cc}
\hline Instância & $H A_{S}$ & $A G_{P M}$ & Melhoria & Tempo $H A_{S}(\mathrm{~s})$ & Tempo $A G_{P M}(\mathrm{~s})$ \\
\hline 1 & 196747,61 & 170328,60 & $-13,43 \%$ & 4,44 & 14,70 \\
2 & 200079,36 & 174484,80 & $-12,79 \%$ & 25,88 & 48,80 \\
3 & 224868,08 & 196315,00 & $-12,70 \%$ & 6,11 & 62,50 \\
4 & 260531,56 & 236559,30 & $-9,20 \%$ & 45,72 & 431,20 \\
5 & 370888,69 & 336440,40 & $-9,29 \%$ & 6,06 & 16,90 \\
6 & 423009,09 & 398538,80 & $-5,78 \%$ & 35,24 & 58,10 \\
7 & 337705,34 & 300885,70 & $-10,90 \%$ & 6,51 & 16,60 \\
8 & 343584,88 & 334956,40 & $-2,51 \%$ & 35,16 & 54,00 \\
9 & 297808,69 & 267511,40 & $-10,17 \%$ & 5,92 & 13,50 \\
10 & 318432,47 & 281749,90 & $-11,52 \%$ & 35,38 & 46,60 \\
11 & 541116,38 & 513127,60 & $-4,54 \%$ & 59,92 & 372,20 \\
\hline Média & & & $-9,27 \%$ & 24,21 & 103,19 \\
\hline
\end{tabular}


Na Tabela 13, a coluna $H A_{S}$ indica o valor da função objetivo para a heurística lagrangiana, a coluna $A G_{P M}$ indica o valor médio da função objetivo para o algoritmo genético, a coluna Melhoria indica a melhoria obtida pelo método proposto em relação ao resultado da heurística lagrangiana e é calculada da forma:

$$
\text { Melhoria }=\frac{\left(A G_{P M}-H A_{S}\right)}{H A_{S}} * 100 .
$$

Os tempos de execução dos métodos são representados em segundos nas colunas Tempo $H A_{S}$ e Tempo $A G_{P M}$.

Podemos observar que o algoritmo genético $A G_{P M}$ apresenta resultados melhores que a heurística lagrangiana, obtendo um planejamento de produção que reduz os atrasos e antecipação na produção dos itens, em média tiveram 9,3\% de melhoria.

A Tabela 14 apresenta os resultados de avaliação da utilização do forno para o algoritmo genético com avaliação via problema da mochila aplicado às 11 instâncias e são comparados com os resultados obtidos pelo $H A_{S}$.

Tabela 14: Utilização do forno pelo algoritmo genético.

\begin{tabular}{c|cc}
\hline Instância & $S u b_{H A_{S}}(\mathrm{~kg})$ & $S u b_{A G_{P M}}(\mathrm{~kg})$ \\
\hline 1 & 1131,30 & $\mathbf{1 0 4 , 1 0}$ \\
2 & 4214,50 & $\mathbf{5 3 6 , 0 0}$ \\
3 & $\mathbf{1 5 , 2 0}$ & 33,00 \\
4 & 155,25 & $\mathbf{1 3 1 , 0 0}$ \\
5 & 867,15 & $\mathbf{8 3 1 , 0 0}$ \\
6 & 1987,00 & $\mathbf{1 5 4 7 , 4 0}$ \\
7 & 1221,00 & $\mathbf{8 4 1 , 1 0}$ \\
8 & 2768,60 & $\mathbf{2 2 6 2 , 3 0}$ \\
9 & 867,15 & $\mathbf{8 3 1 , 0 0}$ \\
10 & 4415,00 & $\mathbf{2 1 0 9 , 0 0}$ \\
11 & 1484,70 & $\mathbf{1 2 1 9 , 6 0}$ \\
\hline Média & 1738,80 & $\mathbf{9 4 9 , 5 9}$ \\
\hline
\end{tabular}

Na Tabela 14, a coluna $S u b_{H A_{S}}$ indica a subutilização do forno em quilos de liga fundida dada pelo planejamento da produção da heurística lagrangiana e a coluna $S u b_{A G_{P M}}$ indica a subutilização do forno em quilos de liga fundida dada pelo planejamento da produção do algoritmo genético.

Podemos observar que o planejamento da produção obtido pelo algoritmo genético, em média, subutiliza menos o forno que o planejamento obtido pelo método da heurística lagrangiana. 


\subsection{Problemas com penalidade para subutilização do forno}

Aplicamos ao algoritmo genético com avaliação via problema da mochila a abordagem com penalidade para subutilização do forno, que é calculada de forma equivalente ao proposto na Seção 6.4. A Tabela 15 mostra os resultados de melhoria da Instância Teste aplicada ao algoritmo genético com penalidade $\left(A G_{P M}^{P}\right)$ quando comparados com o resultado da heurística lagrangiana com penalidade $\left(H A_{C}\right)$. Foram aplicadas penalidades de 25, 50, 75, 100 e 125 por quilo de subutilização do forno.

Tabela 15: Melhoria aplicando a penalidade à subutilização do forno.

\begin{tabular}{c|ccc}
\hline $\begin{array}{c}\text { Penalidade } \\
(\sigma)\end{array}$ & $\begin{array}{c}\text { Melhoria } \\
\text { mínima }\end{array}$ & $\begin{array}{c}\text { Melhoria } \\
\text { média }\end{array}$ & $\begin{array}{c}\text { Melhoria } \\
\text { máxima }\end{array}$ \\
\hline 0 & $-12,22 \%$ & $-13,60 \%$ & $-14,99 \%$ \\
25 & $-9,49 \%$ & $-11,69 \%$ & $-13,57 \%$ \\
50 & $-8,65 \%$ & $-11,45 \%$ & $-12,73 \%$ \\
75 & $-3,95 \%$ & $-8,56 \%$ & $-11,40 \%$ \\
100 & $-3,67 \%$ & $-6,30 \%$ & $-8,40 \%$ \\
125 & $0,25 \%$ & $-3,30 \%$ & $-8,59 \%$ \\
150 & $3,36 \%$ & $-0,86 \%$ & $-6,50 \%$ \\
\hline
\end{tabular}

Na Tabela 15, a coluna Melhoria mínima indica a diferença percentual entre a pior solução encontrada pelo $A G_{P M}^{P}$ e a solução da heurística lagrangiana $\left(H A_{C}\right)$; a coluna Melhoria máxima indica a diferença percentual entre a melhor solução encontrada pelo $A G_{P M}^{P}$ e a solução da $H A_{C}$; a coluna Melhoria média indica a diferença percentual entre a média das soluções encontradas pelo $A G_{P M}^{P}$ e a solução da $H A_{C}$; e foram calculadas da forma:

$$
\text { Melhoria }=\frac{\left(A G_{P M}^{P}-H A_{C}\right)}{H A_{C}} * 100
$$

A Tabela 16 apresenta os resultados de avaliação da utilização do forno para o algoritmo genético com penalidade $\left(A G_{P M}^{P}\right)$ aplicado à Instância Teste.

\begin{tabular}{|c|c|c|c|}
\hline $\begin{array}{c}\text { Penalidade } \\
(\sigma)\end{array}$ & $\begin{array}{c}\text { Subutilização } \\
\text { mínima (kg) }\end{array}$ & $\begin{array}{l}\text { Subutilização } \\
\text { média (kg) }\end{array}$ & $\begin{array}{l}\text { Subutilização } \\
\text { máxima (kg) }\end{array}$ \\
\hline 0 & 1210 & 1219 & 1237 \\
\hline 25 & 663 & 725 & 808 \\
\hline 50 & 432 & 564 & 687 \\
\hline 75 & 303 & 404 & 432 \\
\hline 100 & 196 & 301 & 339 \\
\hline 125 & 142 & 183 & 197 \\
\hline 150 & 98 & 146 & 197 \\
\hline
\end{tabular}

Para a Instância Teste, a heurística lagrangiana com penalidade encontra um planejamento de produção com subutilização do forno de 134,60 quilos. Podemos notar na Figura 17 que 
com o algoritmo genético penalizando a subutilização, é possível obter redução no desperdício, porém, com redução do ganho para a função objetivo. Se considerarmos a penalidade igual a 150, o algoritmo genético e a heurística lagrangiana são competitivas, uma vez que o $A G_{P M}^{P}$ tem um pequeno ganho na função objetivo $(0,9 \%)$, no entanto, tem uma perda de apenas 12 quilos maior que a heurística lagrangiana.
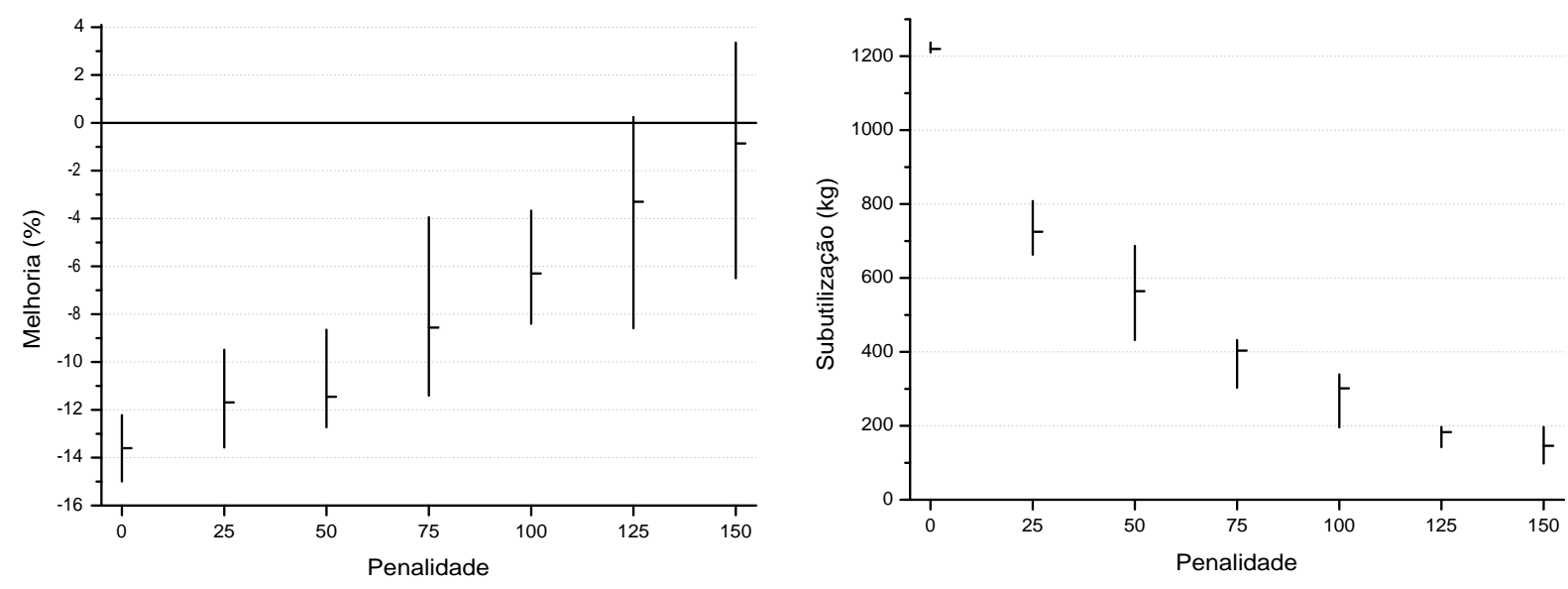

Tabela 17: Penalidade para subutilização do forno.

\subsection{Comparações entre os métodos propostos}

Finalmente, com base no melhor limitante encontrado pelo software de otimização Cplex 7.5, podemos comparar os resultados obtidos pelos métodos propostos neste trabalho e o método proposto por (TONAKI, 2006). Na Tabela 18 apresentamos um resumo dos resultados obtidos.

Tabela 18: Diferença entre as soluções e o melhor limitante.

\begin{tabular}{c|c|cc|cc|cc}
\hline Instância & $M l$ & $H A_{S}$ & GapH $A_{S}$ & $A G_{H L}$ & GapAG $G_{H}$ & $A G_{P M}$ & GapAG $G_{P M}$ \\
\hline 1 & 166370,63 & 196747,61 & $18,26 \%$ & 173411,50 & $4,23 \%$ & 170328,60 & $2,38 \%$ \\
2 & 166347,75 & 200079,36 & $20,28 \%$ & 176960,20 & $6,38 \%$ & 174484,80 & $4,89 \%$ \\
3 & 192921,12 & 224868,08 & $16,56 \%$ & 201160,90 & $4,27 \%$ & 196315,00 & $1,76 \%$ \\
4 & 227727,36 & 260531,56 & $14,41 \%$ & 241338,60 & $5,98 \%$ & 236559,30 & $3,88 \%$ \\
5 & 327140,49 & 370888,69 & $13,37 \%$ & 341633,70 & $4,43 \%$ & 336440,40 & $2,84 \%$ \\
6 & 366684,64 & 423009,09 & $15,36 \%$ & 407545,20 & $11,14 \%$ & 398538,80 & $8,69 \%$ \\
7 & 290092,61 & 337705,34 & $16,41 \%$ & 303213,60 & $4,52 \%$ & 300885,70 & $3,72 \%$ \\
8 & 309128,63 & 343584,88 & $11,15 \%$ & 337654,00 & $9,23 \%$ & 334956,40 & $8,36 \%$ \\
9 & 254066,46 & 297808,69 & $17,22 \%$ & 270312,90 & $6,39 \%$ & 267511,40 & $5,29 \%$ \\
10 & 258528,09 & 318432,47 & $23,17 \%$ & 282248,10 & $9,18 \%$ & 281749,90 & $8,98 \%$ \\
11 & 481605,56 & 541116,38 & $12,36 \%$ & 517074,10 & $7,36 \%$ & 513127,60 & $6,55 \%$ \\
\hline Média & & \multicolumn{7}{c|c}{16,23} & \multicolumn{3}{c}{6,65} & & 5,21 \\
\hline
\end{tabular}

Na Tabela 18, a coluna $M l$ indica o valor do limitante inferior encontrado pelo Cplex, a coluna $H A_{S}$ indica o valor da solução da heurística lagrangiana sem penalidade, a coluna 
$G a p H A_{S}$ indica a diferença percentual entre a solução da heurística lagrangiana sem penalidade e o limitante inferior e é calculada da forma:

$$
G a p H A_{S}=\frac{\left(H A_{S}-M l\right)}{M l} * 100
$$

a coluna $A G_{H L}$ indica o valor médio das soluções do algoritmo genético com avaliação via heurística lagrangiana, a coluna $\operatorname{Gap}_{A} G_{H L}$ indica a diferença percentual entre a solução do algoritmo genético com avaliação via heurística lagrangiana e o limitante inferior e é dada por:

$$
\operatorname{Gap}_{A} G_{H L}=\frac{\left(A G_{H L}-M l\right)}{M l} * 100,
$$

a coluna $A G_{P M}$ indica o valor médio das soluções do algoritmo genético com avaliação via problema da mochila, a coluna $\operatorname{Gap}_{A} G_{P M}$ indica a diferença percentual entre a solução do algoritmo genético com avaliação via problema da mochila e o limitante inferior que é calculada da seguinte forma:

$$
\operatorname{Gap}_{A G_{P M}}=\frac{\left(A G_{P M}-M l\right)}{M l} * 100 .
$$

Podemos observar que a heurística lagrangiana sem penalidade proposta por (TONAKI, 2006) apresenta desvio médio da solução ótima de 16,23\%, o algoritmo genético com avaliação via heurística lagrangiana apresenta desvio médio de 6,65\% e o algoritmo genético com avaliação via problema de mochila apresenta desvio médio de $5,21 \%$ da solução ótima do problema. Na Tabela 19 é apresentada a comparação de utilização do forno para os três métodos.

\begin{tabular}{c|c|c|c}
\multicolumn{4}{c}{ Tabela 19: Comparação entre a utilização do forno. } \\
\hline Instância & $S u b H A_{S}(\mathrm{~kg})$ & $S u b A G_{H L}(\mathrm{~kg})$ & $S u b A G_{P M}(\mathrm{~kg})$ \\
\hline 1 & 1131,30 & 111,14 & 104,10 \\
2 & 4214,50 & 1616,10 & 536,00 \\
3 & 15,20 & 39,81 & 33,00 \\
4 & 155,25 & 171,88 & 131,00 \\
5 & 867,15 & 806,99 & 831,00 \\
6 & 1987,00 & 1906,53 & 1547,40 \\
7 & 1221,00 & 804,29 & 841,10 \\
8 & 2768,60 & 2280,86 & 2262,30 \\
9 & 867,15 & 768,47 & 831,00 \\
10 & 4415,00 & 2902,94 & 2109,00 \\
11 & 1484,70 & 1357,23 & 1219,60 \\
\hline Média & 1738,80 & 1160,57 & 949,59 \\
\hline
\end{tabular}

Na Tabela 19, a coluna $S u b H A_{S}$ indica a subutilização do forno (em quilos) gerada pelo planejamento da heurística lagrangiana proposta por (TONAKI, 2006), a coluna $S u b A G_{H L}$ indica a subutilização do forno (em quilos) gerada pelo planejamento do algoritmo genético com função de avaliação por heurística lagrangiana e a coluna $S u b A G_{P M}$ indica a subutilização do forno (em quilos) gerada pelo planejamento do algoritmo genético com função de avaliação por problema da mochila. 
Considerando a redução apresentada na função objetivo, o $A G_{P M}$ se mostrou mais eficiente, além disso, em média, a subutilização do forno é menor que para o planejamento da produção dos outros métodos. 


\section{Conclusões e trabalhos futuros}

Neste trabalho foi abordado um problema de dimensionamento de lotes aplicado à fundições de pequeno porte que envolve a produção de múltiplos itens, com capacidade limitada e possibilidade de atraso no atendimento da demanda. Além disso, é necessário que seja definida a programação dos períodos em que cada liga terá produção. O objetivo é encontrar um planejamento de produção de ligas e dimensionar o lote das peças com custo mínimo de estoque e de atraso nos pedidos sem exceder a capacidade do forno.

Nossa pesquisa se baseou no modelo proposto em (ARAUJO, 2003) e na decomposição do problema proposta por (TONAKI, 2006). Tonaki (2006) propõe decompor o problema em dois subproblemas de planejamento: o problema de determinar as ligas e o problema de dimensionar os lotes das peças para as ligas a serem fundidas. A autora concluiu que uma melhoria na abordagem de determinação das ligas a serem fundidas poderia melhorar a solução final do problema, uma vez que a heurística para problema de dimensionamento de lotes das peças se mostrou eficiente. Com isso, propusemos um algoritmo genético, independente de qualquer software comercial, para determinar a configuração das ligas e como função de avaliação utilizamos a heurística lagrangiana proposta por Tonaki (2006).

Em (SILVA; MORABITO, 2004), estudam uma abordagem para o dimensionamento de lotes via problema de corte e empacotamento. Com base neste trabalho, propusemos um segundo algoritmo genético que tem como função de avaliação o problema da mochila.

Os resultados computacionais mostram que o algoritmo genético com avaliação via heurística lagrangiana tem desvio médio de $6,6 \%$ da solução ótima e o algoritmo genético com avaliação via problema da mochila tem desvio médio de 5,2\% da solução ótima. Quando os resultados são comparados com a heurística lagrangiana proposta por (TONAKI, 2006), método que também não necessita de software proprietário, o algoritmo genético apresentou melhores soluções para o planejamento da produção que reduz o estoque e o atraso na produção dos itens, com melhorias de $8,1 \%$ e 9,2\% no valor da função objetivo, para as abordagens via heurística lagrangiana e via problema de mochila, respectivamente.

Apesar dos tempos de execução das metaheurísticas propostas serem maiores que a heurística proposta por (TONAKI, 2006), o algoritmo genético com avaliação via problema da mochila é 
competitivo frente aos resultados apresentados, resolvendo o problema em 103 segundos em média. O tempo gasto no planejamento da produção feito manualmente pela fundição é de aproximadamente 2 dias, logo, o tempo de execução do algoritmo genético com avaliação via problema da mochila não é significativo.

Outro ponto a ser destacado é a versatilidade dos parâmetros, o algoritmo genético pode resolver problemas com parâmetros variados, tais como: diferentes períodos de horizonte de planejamento, capacidade do forno e número máximo de fornada por dia; sem a necessidade de alterações no algoritmo.

Tonaki (2006) propôs uma heurística lagrangiana com penalidade para subutilização do forno que obteve uma programação para o forno que utiliza grande parte da capacidade mantendo um valor da função objetivo considerado bom. As penalidade aplicadas aos algoritmos genéticos mostraram que é possível encontrar um planejamento da produção que reduz a subutilização do forno, porém, sem manter a qualidade da solução. A continuação deste trabalho envolve naturalmente a pesquisa de técnicas que encontrem soluções de qualidade para a redução do atraso na entrega dos itens demandados e ao mesmo tempo reduzam a subutilização do forno.

Apesar de termos obtido melhoria no valor da função objetivo com relação à literatura, o tempo computacional se encontra superior ao desejado. A utilização de preprocessamentos na abordagem por heurística lagrangiana, como também na abordagem por problema de mochila podem reduzir o tempo de execução e manter bons resultados.

Também sugerimos buscar outras alternativas para reduzir o tempo computacional do algoritmo. Algumas propostas que poderiam ser estudadas são: uma abordagem de organização da população de forma estruturada hierarquicamente como proposta em (BURIOL et al., 2004) e a avaliação dos indivíduos utilizando heurística lagrangiana período a período.

A utilização do algoritmo genético com avaliação via problema da mochila se mostrou eficiente, logo, é interessante o avanço na pesquisa da abordagem do problema de dimensionamento de lotes das peças utilizando o problema de corte unidimensional e outras aplicações com outros métodos de resolução parecem ser naturais.

Sabemos que resolver o problema período a período é uma relaxação do problema original e, portanto, pode levar a uma solução sub-ótima. Segundo Poldi (2007), a utilização do problema de corte de estoque multiperíodo (PCEM) permite observar todos os períodos do horizonte de planejamento em conjunto, logo, se for vantajoso a produção de itens pode ser antecipada, o que pode levar a ganhos efetivos quando comparados a soluções período a período (lote por lote). Em (POLDI, 2007) é proposta um heurística para o PCEM capaz de resolver o problema de planejamento de produção das peças. Essa adaptação pode permitir uma solução que melhor considere tanto a antecipação quanto o atraso da produção dos itens. 
Outra abordagem para resolver o problema de planejamento de produção das peças é o problema da mochila compartimentada no qual a mochila deve ser dividida em compartimentos onde são acomodados itens com características semelhantes. De forma análoga, temos várias fornadas (compartimentos) que produzem itens de características semelhantes (vazados com a mesma liga). Em (HOTO et al., 2007), (MARQUES; ARENALES, 2007) e (LEãO, 2009), heurísticas são propostas para resolver o problema da mochila compartimentada.

Um algoritmo genético simbiótico foi proposto em (GOLFETO et al., 2007) aplicado ao problema de corte unidimensional que visa determinar os padrões de corte e o número de vezes que cada padrão é utilizado. Futuramente, pode-se desenvolver um algoritmo genético simbiótico capaz de determinar o planejamento das ligas e dimensionar os lotes das peças conjuntamente.

Em resumo, a contribuição desta dissertação foi desenvolver um método capaz de encontrar soluções melhores para o problema de determinação da fundição de ligas metálicas e dos itens associados a serem vazados com objetivo de redução do atraso da produção dos itens demandados. Além disso, uma gama de novas possibilidades foi determinada a partir desta pesquisa para trabalhos futuros. 


\section{Referências Bibliográficas}

ABIFA. Relatório anual. 2005. Disponível em: <http://www.abifa.com.br>.

ARAUJO, S. A. Modelos e métodos para o planejamento e programação da produção aplicado no setor de fundições. Tese (Doutorado) - ICMC-USP, 2003.

ARAUJO, S. A.; ARENALES, M. N. Dimensionamento de lotes e programação do forno numa fundição automatizada de porte médio. Pesquisa Operacional, v. 23, n. 3, p. 403-420, 2003.

ARAUJO, S. A.; ARENALES, M. N. Planejamento e programação da produção numa fundição cativa automatizada de grande porte. Investigação Operacional, v. 24, p. 197-210, 2004a.

ARAUJO, S. A.; ARENALES, M. N.; CLARK, A. R. Dimensionamento de lotes e programação do forno numa fundição de pequeno porte. Gestão \& Produção, v. 11, n. 2, p. 1-20, mai-ago 2004b.

ARAUJO, S. A.; ARENALES, M. N.; CLARK, A. R. Lot-sizing and furnace scheduling in small foundries. Computers and Operations Research., p. 916-932, 2008.

BAHL, H. C.; RITZMAN, L. P.; GUPTA, J. N. D. Determining lot sizes and resources requirements: a review. Operations Research, v. 35, p. 329-345, 1986.

BRAHIMI, N. et al. Single item lot sizing problems. European Journal of Operational Research, v. 168 , p. $1-16,2006$.

BURIOL, L.; FRANçA, P. M.; MOSCATO, P. A new memetic algorithm for the asymmetric traveling salesman problem. Journal of Heuristics, v. 10, p. 483.506, 2004.

DREXL, A.; KIMMS, A. Lot sizing and scheduling - survey and extensions. European Journal of Operational Research, v. 99, p. 221-235, 1997.

DUDA, J. Lot-sizing in a foundry using genetic algorithm and repair functions. In: EvoCOP. [S.1.]: Springer, 2005. (Lecture Notes in Computer Science), p. 101-111.

DUDA, J.; OSYCZKA, A. Multiple criteria lot-sizing in a foundry using evolutionary algorithms. Springer, p. 651-663, 2005.

FERNANDES, F. C. F.; LEITE, R. B. Automação industrial e sistemas informatizados de gestão da produção em fundições de mercado. Gestão $\mathcal{E}$ Produção, v. 9, n. 3, p. 313-344, dez 2002. Disponível em: <http://www.scielo.br/pdf/gp/v9n3/14572.pdf>.

FINK, C. A programação da produção em fundições de pequeno porte: modelagem matemática e métodos de solução. Dissertação (Mestrado) - Instituto de Ciências Matemáticas e de Computação - ICMC-USP, 2007.

GOLDBERG, D. E. Genetic Algorithm in Search, Optimization, and Machine Learning. [S.1.]: Addison-Wesley Publishing Company, Inc., 1989. 
GOLFETO, R. R.; MORETTI, A. C.; NETO, L. L. de S. Algoritmo genético simbiótico aplicado ao problema de corte unidimensional. Anais do XXXIX Simpósio Brasileiro de Pesquisa Operacional, 2007.

GRAVEL, M.; PRICE, W. L.; GAGNé, C. Scheduling jobs in an alcan aluminium foundry using a genetic algorithm. Internacional Journal of Production Research, v. 38, n. 13, p. 3031-3041, 2000.

HOLLAND, J. H. Adaptation in Natural and Artificial Systems. [S.l.]: MIT Press/Bradford Books, 1992.

HOTO, R.; ARENALES, M. N.; MACULAN, N. The one dimensional compartmentalised knapsack problem: A case study. European Journal of Operational Research, v. 183, p. 1183-1195, 2007.

JANS, R.; DEGRAEVE, Z. Meta-heuristics for dynamic lot sizing: A review and comparison of solution approaches. European Journal of Operational Research, v. 177, p. 1855-1875, 2006.

JANS, R.; DEGRAEVE, Z. Modeling industrial lot sizing problems: a review. Internacional Journal of Production Research, v. 46, n. 6,, p. 1619-1643, March 2008.

KARIMI, B.; GHOMI, S. F.; WILSON, J. The capacitated lot sizing problem: a review of models and algorithms. Omega, v. 31, p. 365-378(14), October 2003. Disponível em: <http://www.ingentaconnect.com/content/els/03050483/2003/00000031/00000005/art00059>.

LANDMANN, R. Um modelo heurístico para a programação da produção em fundições com utilização da lógica Fuzzy. Tese (Doutorado) - Universidade Federal de Santa Catarina, Florianópolis, 2005.

LANDMANN, R. et al. Programação da produção em empresas metalúrgicas com utilização de algoritmo genético. In: . [S.1.]: ENEGEP, 2006.

LARRANAGA, P.; LOZANO, J. A. Estimation of Distribution Algorithms: A New Tool for Evolutionary Computation. Norwell, MA, USA: Kluwer Academic Publishers, 2001. ISBN 0792374665 .

LEãO, A. A. S. Geração de colunas para problemas de corte em duas fases. Dissertação (Mestrado) - ICMC-USP, 2009.

MAES, J.; MCCLAIN, J. O.; WASSENHOVE, L. N. V. Multilevel capacitated lotsizing complexity and lp-based heuristics. European Journal of Operational Research, v. 53, p. 131-148, 1991.

MAN, K.; TANG, K.; KWONG, S. Genetic algorithms: concepts and applications [in engineering design]. Industrial Electronics, IEEE Transactions on, v. 43, n. 5, p. 519-534, Oct 1996. ISSN 0278-0046.

MARQUES, F. P. O problema da mochila compartimentada e aplicações. Tese (Doutorado) Instituto de Ciências Matemáticas e de Computação - ICMC-USP, Outubro 2004.

MARQUES, F. P.; ARENALES, M. N. The constrained compartmentalised knapsack problem. Computers and Operations Research, v. 34, p. 2109-2129, 2007.

POLDI, K. C. O problema de corte de estoque multiperíodo. Tese (Doutorado) - Instituto de Ciências Matemáticas e de Computação - ICMC-USP, 2007. 
SAIT, S. M.; YOUSSEF, H. Iterative Computer Algorithms with Applications in Engineering: solving combinatorial optimization problems. Los Alamitos, CA, USA: IEEE Computer Society, 1999. ISBN 0769501001.

SANTOS-MEZA, E.; SANTOS, M. O.; ARENALES, M. N. A lot-sizing problem in an automated foundry. European Journal of Operational Research, v. 139, p. 490-500, 2002.

SILVA, R. J.; MORABITO, R. Otimização da programação de cargas de forno em uma fábrica de fundição em aço-inox. Gestão $\mathscr{E}$ produção, v. 11, p. 135-151, 2004. Disponível em: $<$ http://www.scielo.br/pdf/gp/v11n1/a12v11n1.pdf $>$.

SRINIVAS, M.; PATNAIK, L. M. Genetic algorithms: A survey. Computer, IEEE Computer Society Press, Los Alamitos, CA, USA, v. 27, n. 6, p. 17-26, June 1994. ISSN 0018-9162. Disponível em: <http://portal.acm.org/citation.cfm?id=187709.187711>.

TEIXEIRA.JR., R. F.; FERNANDES, F. C. F.; PEREIRA, N. A. Aplicações de algoritmos genéticos para elaboração da programação da produção em fundições de mercado. In: . [S.l.]: ENEGEP, 2005.

TEIXEIRA.JR., R. F.; FERNANDES, F. C. F.; PEREIRA, N. A. Sistema de apoio à decisão para programação da produção em funcições de mercado. Gestão $\mathcal{E}$ produção, v. 13, n. 2, p. 205-221, mai-ago 2006.

TEIXEIRA.JR., R. F.; FERNANDES, F. C. F.; PEREIRA, N. A. Um modelo de programação inteira binária para programação da produção em fundições de mercado. In: . [S.l.]: ENEGEP, 2006.

TOLEDO, F. M. B.; ARMENTANO, V. A. A lagrangean-based heuristic for the capacitated lot-sizing problem in parallel machines. European Journal of Operational Research, v. 175, p. 1070-1083, 2006.

TONAKI, V. S. Uma heurística para o problema de dimensionamento de lotes em fundições de mercado. Dissertação (Mestrado) - Instituto de Ciências Matemáticas e de Computação ICMC-USP, 2006. Disponível em: <http://www.teses.usp.br/teses/disponiveis/55/55134/tde$24012007-142604 />$.

TONAKI, V. S.; TOLEDO, F. M. B. An approach to solve the lot sizing and scheduling problem in market-driven foundries. Journal of Operational Research Society, 2009.

VILELA JUNIOR, A. Planejamento e programação da produção numa fundição automatizada de grande porte utilizando uma heurística lagrangiana. Dissertação (Mestrado) - Universidade Estadual de Maringá, 2007.

WOLSEY, L. Solving multi-item lot-sizing problems with an mip solver using classification an reformulation. Management Science, v. 48, p. 1587-1602, 2002.

ZANGWILL, W. A backlogging model and multi-echelon model of a dynamic economic lot size production system - a network aproach. Management Science, v. 15, p. 506-527, 1969. 